\title{
A coupling module for tides, surges and waves
}

\author{
José Ozer ${ }^{\mathrm{a}, *}$, Roberto Padilla-Hernández ${ }^{\mathrm{b}}$, Jaak Monbaliu ${ }^{\mathrm{b}}$, \\ Enrique Alvarez Fanjul ${ }^{\mathrm{c}}$, Juan Carlos Carretero Albiach ${ }^{\mathrm{c}}$, \\ Pedro Osuna ${ }^{\mathrm{b}}$, Jason C.S. Yu ${ }^{\mathrm{b}, 1}$, Judith Wolf ${ }^{\mathrm{d}}$
}

${ }^{\text {a } M a n a g e m e n t ~ U n i t ~ o f ~ t h e ~ N o r t h ~ S e a ~ M a t h e m a t i c a l ~ M o d e l s, ~ G u l l e d e l l e ~ 100, ~ B-1200 ~ B r u s s e l s, ~ B e l g i u m ~}$

${ }^{\mathrm{b}}$ Hydraulics Laboratory, Katholieke Universiteit Leuven, de Croylaan 2, B-3001 Heverlee, Belgium

c Programa de Clima Marítimo (Ente Público Puertos del Estado), Antonio López 81, E-28026 Madrid, Spain

${ }^{\mathrm{d}}$ Proudman Oceanographic Laboratory, Bidston Observatory, Birkenhead CH43 7RA, UK

\begin{abstract}
A generic module in which tides, surges and waves are incorporated has been developed, tested and prepared for dissemination within the framework of the MAST III PROMISE (PRe-Operational Modelling In the Seas of Europe) project. Two existing pre-operational numerical models, a wave model and a hydrodynamic model, were incorporated into a coupling framework that allows an efficient exchange of information between them. Minimal adaptation of the models was needed.

The module has then been implemented and applied to the North Sea, then a series of experiments were performed to investigate the sensitivity of waves and surges to coupling. These experiments show that the sensitivity of waves to coupling increases from deep to shallow water. The sensitivity of surges is more uniformly distributed.

The sensitivity of surges to coupling along the Spanish coast was also studied. The model results were less sensitive than in the North Sea. This is explained by the relative importance of the two forcing components, the atmospheric pressure and the wind stress, in both areas. (C) 2000 Elsevier Science B.V. All rights reserved.
\end{abstract}

Keywords: Coupling; Surges; Tides; Waves

\footnotetext{
* Corresponding author. Fax: +32-2-770-6972.

E-mail address: j.ozer@mumm.ac.be (J. Ozer).

${ }^{1}$ Present address: Department of Marine Environment and Engineering, NSYSU, 70 Lien-Hai Road, Kaoshiung 804, Taiwan.
} 


\section{Introduction}

One of the many objectives of PROMISE (PRe-Operational Modelling In the Seas of Europe) was 'to rationalise the application of pre-operational tidal, storm, turbulence and wave models and to determine how these can be improved depending on the range of processes incorporated'. To achieve this objective, PROMISE partners have developed generic modules incorporating several processes. These modules have been tested and used in various applications. They are now ready to be disseminated for application in other coastal areas and for broader management applications. Prandle (2000, this volume) gives a general overview, while more detailed information can be found in the other papers of this volume.

From the review of existing operational oceanography services (Flather, 2000, this volume), it is clear that for the time being, wave and storm surge predictions in the North Sea are still made separately in most operational centres.

There are, however, several known mechanisms through which each component of the total motion affects the others. Heaps (1983) had already identified the need for a wave model to improve the specification of wind stress in surge models. Various interaction mechanisms (e.g. the surface drag) were identified as potentially important (Wolf et al., 1988). Some results from early attempts at coupling are given in $\mathrm{Wu}$ and Flather (1992). Tolman (1990) concluded from his investigation into the effects of tides and storm surges on wind waves that 'both the instationarity and the inhomogeneity of depth and current play a significant role in wave-tide interaction' and recommended further investigations into the effects of wave-tide interactions on wave heights. Mastenbroek et al. (1993) clearly show the influence of a wave-dependent surface drag coefficient on surge elevations. Even if these surge elevations can be reproduced with an appropriate 'tuning' of this parameter in conventional wind stress formulations (the dimensionless constant $\alpha$ in the Charnock relation (Charnock, 1955) in this case), they argue that 'a wave-dependent drag is to be preferred for storm surge modelling'. A summary of the contributions to coupling, up to the end of the WAM project, is given by Burgers et al. (1994) and Cavaleri et al. (1994).

Davies and Lawrence (1994) notice a significant change of the tidal amplitude and phase in shallow near-coastal regions due to enhanced frictional effects associated with wind-driven flow and wind wave turbulence.

The development, testing and preparation for dissemination of a generic module in which tides, surges and waves are incorporated within the frame of PROMISE, has been considered as a step forward in respect of these studies. The main purpose of this paper is to describe how the module has been developed and to report on a series of experiments dealing with the sensitivities of both models to coupling.

In Section 2, the basic tools are briefly described, the modifications imposed by the coupling are summarised and the way each component may influence the others is discussed. In Section 3, the implementation of the models in the North Sea is presented. A short discussion on the atmospheric forcing during the test period (February 1993) and on the model results (when run separately) follows. Section 4 deals with the presentation of the experiments performed to investigate the sensitivity of the models to coupling and with a detailed investigation of the results of these experiments. While the 
North Sea is the main area of interest in this paper, there have been other coupling experiments made during the course of PROMISE. A short overview of the importance of coupling in the areas where these experiments have been conducted is presented in Section 5. A summary is given and conclusions are drawn in the last section.

\section{Development of a generic module for combined modelling of tides, surges and waves}

\subsection{Introduction}

The following steps have been performed, with the intention of preparing for dissemination, a tool which enables the combined modelling of tides, surges and waves at the North Sea scale and in shallow water. Firstly, two models were chosen. Secondly, model equations were adapted, where necessary, to account for interactions between processes. Finally, model codes were modified for an efficient and correct exchange of information. An overview of the two models with a discussion of the modifications imposed by coupling at the level of model equations is given below. Coding aspects are subsequently addressed.

\subsection{Overview of the models}

\subsubsection{The wave model}

The WAM-cycle4 model (Günther et al., 1992; Komen et al., 1994) is now run operationally at different European centres (see Flather, 2000, this volume). It has been used in most of the wave model applications made during the course of PROMISE (see, Monbaliu et al., 2000, this volume). The only exception is the so-called K-model used in the Sylt-Rømø applications (Schneggenburger et al., 2000, this volume).

The evolution of the wave spectrum, without any presumption on its shape, is described by the spectral energy balance equation (SWAMP group, 1985). The physics of wave evolution, for the full set of degrees-of-freedom of a $2 \mathrm{D}$ spectrum, is represented in accordance to our present knowledge. The governing equation includes advection in geographical and spectral (direction and frequency) space, wind input (Janssen, 1989, 1991), dissipation due to white-capping (Günther et al., 1992), nonlinear interactions (Hasselmann et al., 1985) and bottom friction. The latter can be computed according to different models, ranking from the simplest proposed by Hasselmann et al. (1973) to formulations accounting for a combined wave-current field (e.g., Madsen, 1994; Christoffersen and Jonsson, 1985).

Depth and current refraction are included in the model equations. The interaction of the waves with the mean flow is implicitly taken into account through the advection in the frequency space. In the action density balance equation formulated in terms of energy (Monbaliu et al., 2000, this volume), this term reads

$$
\sigma \frac{\partial}{\partial \sigma}\left(c_{\sigma} \frac{F}{\sigma}\right)=\frac{\partial}{\partial \sigma}\left(c_{\sigma} F\right)-\frac{F}{\sigma} c_{\sigma}
$$


where $F$ is the wave energy density spectrum, $\sigma$ the intrinsic or relative frequency and $c_{\sigma}$ the propagation velocity in the relative frequency space. The first term of the right hand side is the flux of energy in $\sigma$ space and the second one describes the interaction of the wave energy with the mean flow (Phillips, 1977).

With time- and space-dependent depth and current fields, the propagation velocity in the relative frequency space should be computed according to (e.g., Le Blond and Mysak, 1978; Tolman, 1990)

$$
c_{\sigma}=\frac{\partial \sigma}{\partial d}\left[\frac{\partial d}{\partial t}+\vec{u} \cdot \vec{\nabla} d\right]-c_{\mathrm{g}} \vec{k} \cdot \frac{\partial \vec{u}}{\partial s} .
$$

$t$ is the time coordinate, $s$ is the space coordinate in the direction of propagation, $\vec{\nabla}$ the gradient operator in the geographical space, $d$ is the total depth $(H+\eta$, mean sea level + surface elevation), $\vec{u}$ is the current, $c_{\mathrm{g}}$ is the group velocity and $\vec{k}$ is the wave number vector. However, in the original formulation of the model, current and water depth were assumed to be time-independent, hence the term $\partial d / \partial t$ in Eq. (2) is omitted. Tolman (1990) concluded from his experiments that 'both the instationarity and the inhomogeneity of depth and current play a significant role in wave-tide interaction'. In shallow water areas, with tidal amplitudes of $O(2 \mathrm{~m})$ and tidal currents running mainly perpendicular to the depth gradients, $\left(\partial d / \partial t\right.$ ) (of the order of $\sim 10^{-4} \mathrm{~m} \mathrm{~s}^{-1}$ ) should be significantly greater than $\vec{u} \cdot \nabla d$ (see Section 4).

The frequency spectrum is transformed from relative to absolute frequency $\Omega=\sigma+$ $\vec{k} \cdot \vec{u}$ at all outputs to account for the Doppler effect.

The WAM equations have not been modified for model runs in coupled mode, which means that the time derivative of the depth is still not included (Eq. (2)). For these runs, new current and water depth fields are introduced into the model at regular time intervals. Using these new fields, some arrays (e.g., wave number and group velocity) that were only computed once in the pre-processing of WAM are updated. Note that for some depth-dependent parameters and/or coefficients, their evolution in time due to tide and surge is not as smooth as it should be. Indeed, their values are only known for a discrete set of depth values (the shallow water depth table). As time passes, it is the pre-computed value corresponding to the depth closest to the actual depth that is used.

Almost all the terms in the governing equation are affected in one way or another by time and space varying currents and water depths. These modify the propagation velocity in the geographical and spectral spaces. Interactions between the wave field and the mean flow can, locally, be a source or a sink of wave energy. Current and depth gradients redistribute energy density in the spectral space. Through the dispersion relationship, the wave numbers become time dependent. This makes the analysis of the influence of coupling on the wave model results particularly difficult.

\subsubsection{The hydrodynamic model}

The hydrodynamic model is a revised version of an existing operational model used to forecast storm surges in the North Sea (van den Eynde et al., 1995). It is a conventional, vertically integrated, two-dimensional 'shallow water wave equations' model. The model state variables are the depth-averaged current and the elevation of the free surface with respect to mean sea level. 
The model is forced by the tide (four semi-diurnal and four diurnal tidal constituents) and the inverse barometric effect along the open boundaries, the atmospheric pressure gradients and the wind stress in the area. A zero normal flux is imposed along the solid boundaries.

Conventional quadratic laws are used to compute surface and bottom stresses. The equation for the surface stress is

$$
\vec{\tau}_{\mathrm{s}}=\rho_{\mathrm{a}} C_{\mathrm{s}}|\vec{W}| \vec{W}
$$

where $\rho_{\mathrm{a}}$ is the air density $\left(1.23 \mathrm{~kg} \mathrm{~m}^{-3}\right), \vec{W}$ is the wind speed at $10 \mathrm{~m}$ above the sea surface and $C_{\mathrm{s}}$ is the surface drag coefficient. Various surface drag coefficients are proposed in the literature. We generally used the one proposed by Heaps (1965)

$$
\begin{array}{ll}
C_{\mathrm{s}}=0.565 \times 10^{-3} & \text { for } W \leq 5 \mathrm{~m} \mathrm{~s}^{-1} \\
C_{\mathrm{s}}=(-0.12+0.130 W) \times 10^{-3} & \text { for } 5<W<19.22 \mathrm{~m} \mathrm{~s}^{-1} \\
C_{\mathrm{s}}=2.513 \times 10^{-3} & \text { for } W \geq 19.2 \mathrm{~m} \mathrm{~s}^{-1}
\end{array}
$$

Bottom friction is computed by

$$
\vec{\tau}_{\mathrm{b}}=\rho_{w} C_{\mathrm{b}}|\vec{u}| \vec{u}-m \vec{\tau}_{\mathrm{s}}
$$

where $\rho_{\mathrm{w}}$ is the water density $\left(1023 \mathrm{~kg} \mathrm{~m}^{-3}\right), \vec{u}$ is the depth mean current and $C_{\mathrm{b}}$ is the bottom drag coefficient (0.00243).

It is not unusual in 2D storm surge models (see for example, Groen and Groves, 1962; Heaps, 1967; Ronday, 1976) to modify the bottom stress so that there is a component directly related to the wind stress (a crude way to account for the vertical structure of the wind-driven current). The coefficient $m$ is generally set equal to 0.1 . Note that this term is introduced into the computation of the surface stress instead of the bottom friction in the computer code (see Section 4).

Waves can influence the mean flow in three different ways: through the spatial gradients of the radiation stress, by changing the wind stress, and by affecting the bottom friction.

2.2.2.1. Radiation stress. The radiation stress represents the contribution of the wave motions to the mean horizontal flux of horizontal momentum. It is expressed in terms of the wave spectrum. The computation of the radiation stress and its implementation in the model equations follows that of Mastenbroek et al. (1993).

2.2.2.2. Surface stress. The variation of the surface drag with wind speed as shown in Eq. (3) is an empirical concept that reflects the increase of the sea surface roughness with increasing wind speed.

The wave field largely determines the change of sea surface roughness with wind speed. There is experimental evidence of a certain dependency between wind stress and wave age (see for example, Maat et al., 1991; Monbaliu, 1994). In recent years, different parameterisations for computing the surface stress as function of wind and waves have been proposed (Makin and Chalikov, 1986; Janssen, 1991). Janssen's theory is implemented in WAM-cycle4. 
2.2.2.3. Bottom friction. In shallow waters, the waves interact with the bottom and the orbital motions of the low frequency gravity waves to cause an alternating current in its vicinity. This current originates from a thin boundary layer (typically a few centimetres) in which the level of turbulence is increased, causing an enhancement of the bottom stress felt by the current (Christoffersen and Jonsson, 1985; Gross et al., 1992). In WAM-cycle4, bottom dissipation due to the combined effect of current and waves can be computed either following the approach proposed by Madsen (1994) or following the approach proposed by Christoffersen and Jonsson (1985).

The adaptation of the hydrodynamic model for runs in the coupled mode is as follows. The spatial derivatives of the radiation stress were introduced in the momentum equation. The surface stress is no longer computed according to Eq. (3) but directly transferred from WAM to the model at regular time intervals. While it is certainly an interesting subject for further research, the influence of combined waves and currents on bottom dissipation (for waves and/or for currents) has not been investigated in the experiments reported here. To our knowledge, the routines that allow the modelling of bottom dissipation due to waves and currents still needs to be tested in a realistic configuration.

\subsection{Coupling procedure}

A general purpose framework has been specifically developed during the course of PROMISE with the intention of preparing for dissemination, tools that allow the combined modelling of tides, surges and waves at the North Sea scale and in shallow water. This framework is presented on Fig. 1.

In the PROMISE coupling framework, the two models (i.e., the hydrodynamic model and the wave model) are taken as subroutines of a main program (CHIEF) that controls

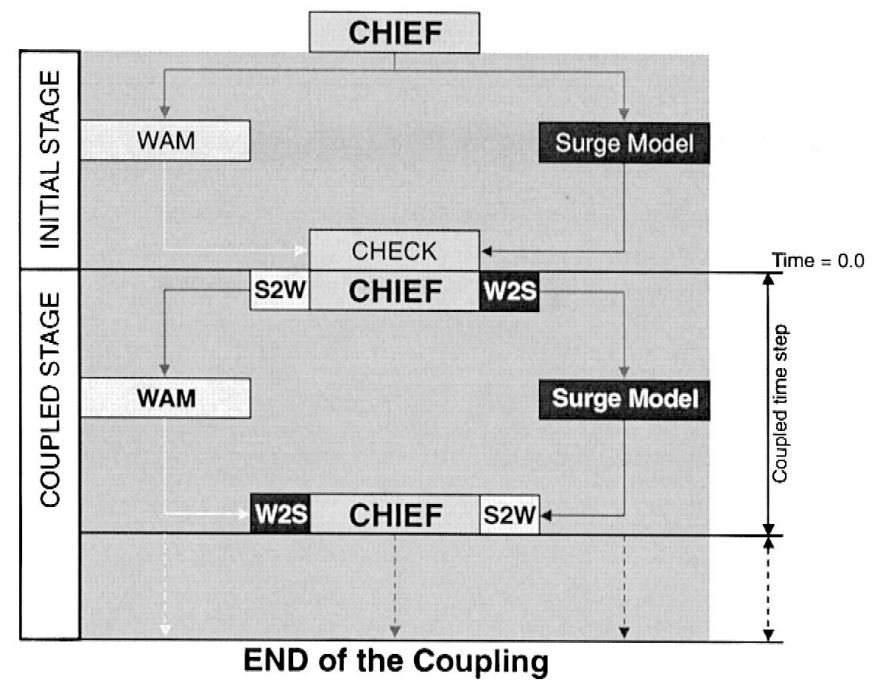

Fig. 1. The PROMISE coupling framework. 
their execution. It takes care of the initialisation of both models, and verifies their status at the start time of coupling. During the coupled mode, it calls the subroutines needed to transfer the information between the two model grids. All North Sea applications have been made with this coupling framework.

\section{North Sea applications}

\subsection{Implementation}

For the North Sea applications, the two models have been implemented on a relatively coarse grid covering approximately the region $48-71^{\circ} \mathrm{N}, 12^{\circ} \mathrm{W}-12^{\circ} \mathrm{E}$. The bottom topography and coastlines in this area are presented in Fig. 2. The horizontal resolution is equal to $1 / 2^{\circ}$ longitude and $1 / 3^{\circ}$ latitude. The bottom topography is taken from the Northeast Atlantic model developed by Flather (1981).

Such an implementation has to be seen as a first step in the development of an operational model for the forecast of waves, tides and surges in coastal areas. Indeed, it is not unusual to start with such an implementation in a wave forecasting system. The desired horizontal resolution in the coastal area of interest is then obtained through

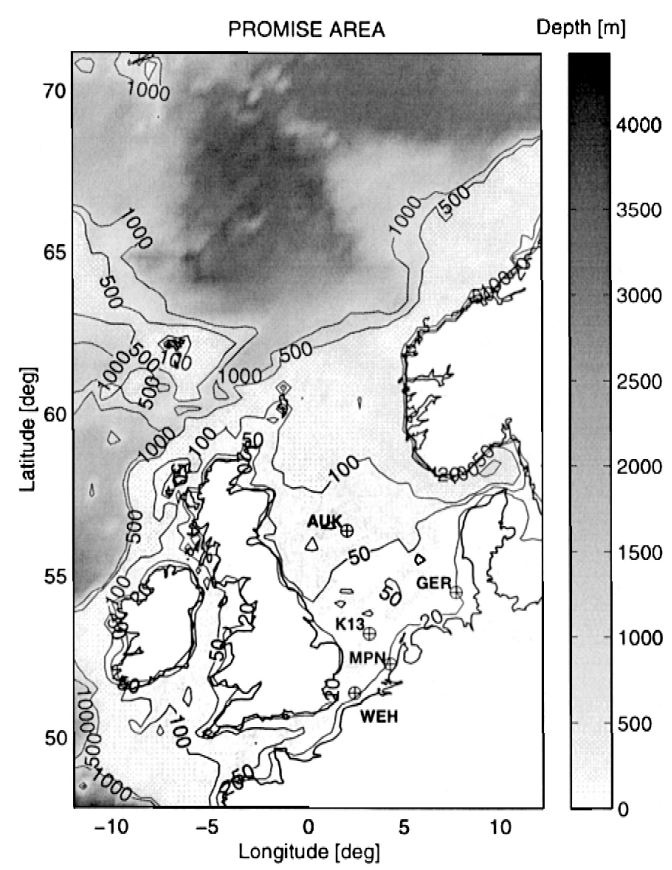

Fig. 2. Model area for the North Sea sensitivity study. Depths are given in metres. The position of the five stations used for the analysis of time series is also given. 
successive nesting. The same nesting procedure will be later developed for the combined model.

In Fig. 2, the positions of the five stations at which model results are investigated in more details are also shown. The exact geographical locations of these stations as well as information on the mean depth and the characteristics of the tidal range are given in Table 1.

Tidal currents at Auk are rather weak. At K13, the tidal ellipse is nearly circular and the currents are of the order of $0.5 \mathrm{~m} \mathrm{~s}^{-1}$. At the station Ger, the tidal ellipse is rather flat with nearly a west-east orientation. Tidal currents are also of the order of $0.5 \mathrm{~m}$ $\mathrm{s}^{-1}$. A southwest-northeast orientation of tidal currents is observed at both stations Weh and Mpn. Tidal currents at station Weh $\left(0.70 \mathrm{~m} \mathrm{~s}^{-1}\right)$ are nearly two times as large as those at Mpn.

In the hydrodynamic model, the amplitude and phase of the eight constituents used to define the tidal forcing are also taken from the Flather's Northeast Atlantic model. The model equations are integrated with a time step equal to $75 \mathrm{~s}$.

In WAM, a logarithmic shallow water depth table contains 63 values starting at a depth of $2 \mathrm{~m}$ and increasing successively by a factor of 1.1. The frequency grid is also logarithmic with $f$ increasing successively by a factor of 1.1 . It starts at 0.04 and has 25 values. A resolution of $30^{\circ}$ is used in the directional space. The source term integration time step and the propagation time step are both $600 \mathrm{~s}$. Propagation is computed in a quadrant coordinate system (see also Monbaliu et al., 2000, this volume).

\subsection{Results for a run in uncoupled mode}

\subsubsection{Reference run}

In the first experiment, the models were run without exchanging any information. This run will be referred to as the reference run. The period for the simulation is the month of February 1993. The same period has been used for the PROMISE North Sea WAM model intercomparison (Monbaliu et al., 1997). An overview of the atmospheric forcing during that month is first given. Model results are discussed afterwards.

\subsubsection{Atmospheric conditions}

The atmospheric forcing is taken from the UK Met. Office forecast routinely received for storm surge predictions (van den Eynde et al., 1995). For the model runs in hindcast

Table 1

Location, mean depth and tidal range at the five stations considered in this study. Note that water depths are taken from bathymetric data used by the two models at the nearest grid point

\begin{tabular}{lllll}
\hline Station & Latitude & Longitude & Mean depth $(\mathrm{m})$ & Tidal range $(\mathrm{m})$ \\
\hline Auk & $56^{\circ} 23^{\prime} 59^{\prime \prime}$ & $2^{\circ} 03^{\prime} 56^{\prime \prime}$ & 80 & 0.8 \\
Ger & $54^{\circ} 30^{\prime} 00^{\prime \prime}$ & $7^{\circ} 45^{\prime} 00^{\prime \prime}$ & 21 & 1.6 \\
K13 & $53^{\circ} 13^{\prime} 01^{\prime \prime}$ & $3^{\circ} 13^{\prime} 12^{\prime \prime}$ & 31 & 1.2 \\
Mpn & $52^{\circ} 16^{\prime} 26^{\prime \prime}$ & $4^{\circ} 17^{\prime} 46^{\prime \prime}$ & 18 & 1.2 \\
Weh & $51^{\circ} 22^{\prime} 56^{\prime \prime}$ & $2^{\circ} 26^{\prime} 20^{\prime \prime}$ & 31 & 2.8 \\
\hline
\end{tabular}


mode, atmospheric pressure and wind speed are available at 6-h intervals, on a $1.25^{\circ}$ latitude/longitude grid. Each day, at 00:00 GMT and 12:00 GMT, the information corresponds to a 'nowcast' (i.e., a previous model forecast corrected by assimilation of in situ observations). At 06:00 GMT and 18:00 GMT, a model forecast is used. A spatial interpolation is performed to obtain the atmospheric pressure and the wind speed at the grid-nodes. A linear interpolation is made at each time step in the hydrodynamic model while the wind speed is kept constant during $6 \mathrm{~h}$ in the wave model (see Section 4 ).

Time series of wind speed at the five stations are presented in Fig. 3. Winds are relatively weak, $O\left(5 \mathrm{~m} \mathrm{~s}^{-1}\right)$ between the 5th and 15th February. Three relatively important wind events, with wind speed up to $25 \mathrm{~m} \mathrm{~s}^{-1}$, occur between the 15 th and 25th February. Each event lasts about 2 days. During these events, the winds are stronger in the central North Sea (station Auk) than in the southern Bight (stations K13 and Weh) and close to the coasts (stations Ger and Mpn). Comparisons between these winds and in situ measurements (Ovidio et al., 1995) indicate that the quality of these predicted winds is quite good during that time (a bias less than $0.5 \mathrm{~m} \mathrm{~s}^{-1}$ and a scatter index of around 0.2).

The descriptions for the three wind events are nearly the same. A relatively high and stable pressure system exists in the southwestern part of the area. A low pressure enters the north of the region through the western boundary. It traverses the North Sea eastwards and then turns to the southeast. It leaves the region crossing over Germany. The atmospheric situation at 00:00 GMT 21st February is depicted in Fig. 4. These three 'northwest' storms generate northwesterly winds over the North Sea.

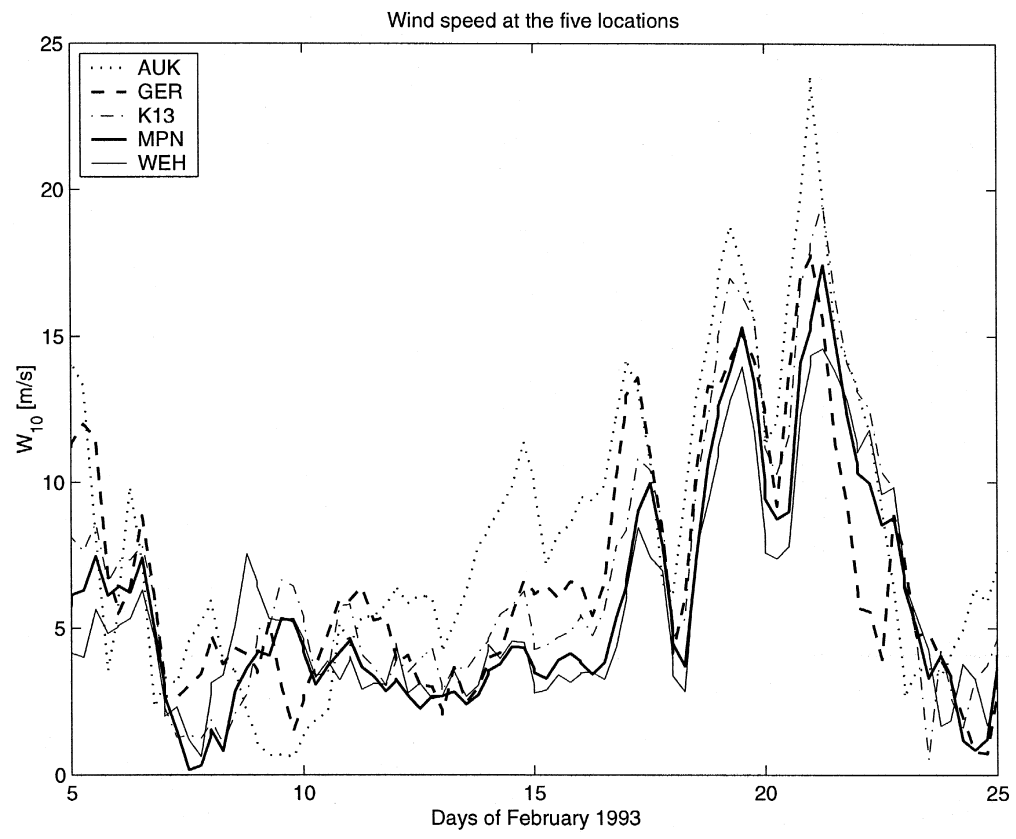

Fig. 3. Time series of the wind speed at five stations from 5-25th February 1993. 


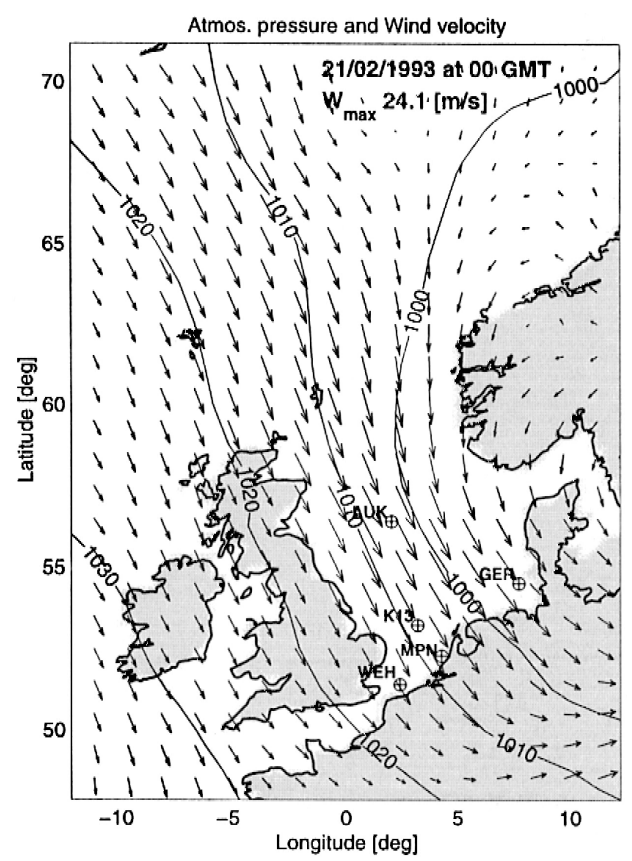

Fig. 4. Atmospheric situation at 00:00 GMT 21st February 1993. Atmospheric pressure in h Pa and wind speed in $\mathrm{m} \mathrm{s}^{-1}$.

\subsubsection{Model results}

Time series of significant wave height $\left(H_{\mathrm{S}}\right)$, peak period $\left(T_{\mathrm{p}}\right)$ and surge elevation $\left(\eta_{s}\right)$ at the five stations are presented in Fig. 5.

The results of the WAM reference run are discussed at length by Monbaliu et al. (1997, 1999). Waves are relatively small during the first part of the month. Higher waves are observed during the stormy period (16-23rd February). At that time, waves are significantly higher in the central North Sea than in the Southern Bight and coastal areas. Comparison with in situ measurements indicates that the model tends to underpredict wave height (at station Auk, the bias, for the whole month, is of the order of 0.4 $\mathrm{m}$; at station $\mathrm{K} 13$, it is of the order of $0.1 \mathrm{~m}$ ).

The results of the hydrodynamic model (Fig. 5c) are explained below.

The negative surge observed (Fig. 5c) at all stations during the first part of the month (5-15th February) is due to the atmospheric pressure (inverse barometric effect along the open boundary, horizontal pressure gradients inside the area). The wind has very little influence during that time.

During the storm events, the wind blowing towards south-southeast generates positive surge elevations that exceed $2 \mathrm{~m}$ in the southern North Sea (stations Mpn and Weh). From a comparison with observations at one station along the Belgian coast, one can say that the model also seems to under-predict the surge elevations (at the peak of the third surge, the surge elevation is underestimated by about $0.15 \mathrm{~m}$ ). 

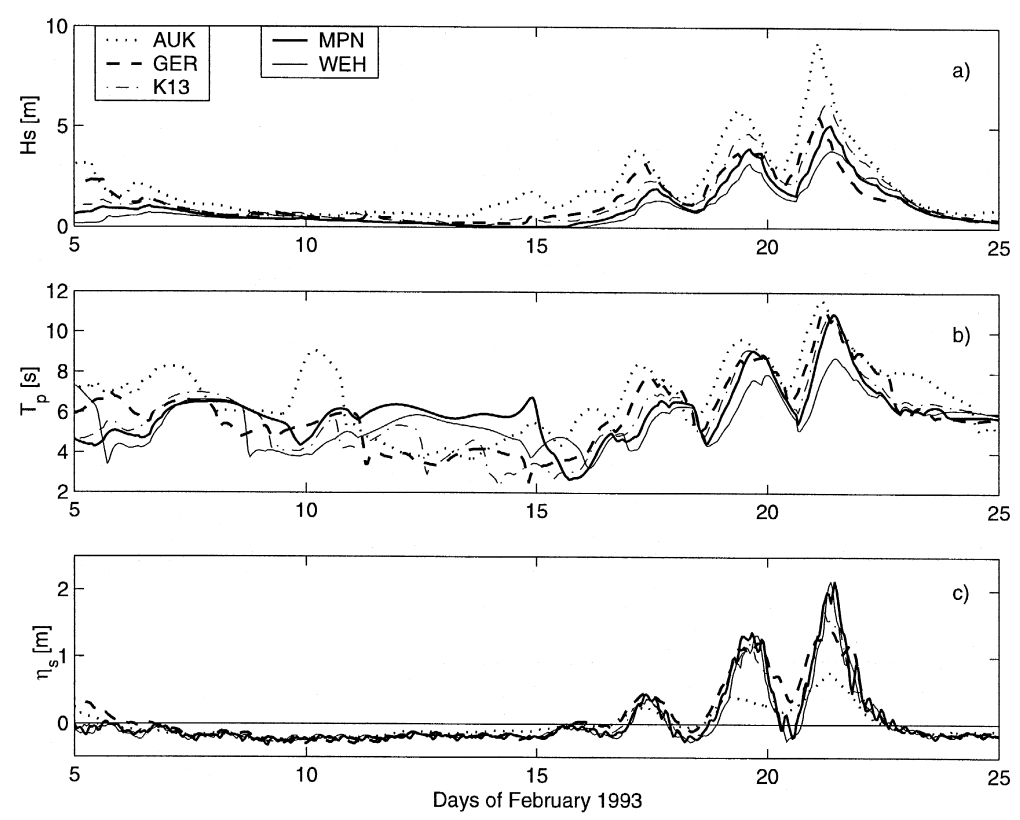

Fig. 5. Time series of $H_{\mathrm{S}}$ (top), $T_{\mathrm{p}}$ (centre) and $\eta_{\mathrm{s}}$ (bottom) at the five stations for the reference run 5-25th February 1993.

While any model intended for operational use needs an in-depth comparison with in situ measurements and a proper calibration, this is considered outside the scope of this study. The focus is primarily on the study of the sensitivity of the models to coupling. Interesting discussions of wave-current interaction observations in the Holderness area are given by Wolf (1999) and by Wolf and Prandle (1999). An illustration of observed tidal modulation at the station Weh is given by Monbaliu et al. (1998).

\section{North Sea sensitivity analysis}

\subsection{Description of the experiments}

To assess the sensitivity of the model results to various degrees of coupling, a series of model runs have been completed. Only some of them are discussed in detail in this paper. Others will be briefly mentioned where appropriate.

All these experiments follow the same scheme. The start time of coupling is at 06:00 GMT 1st February 1993. The hydrodynamic model, starting with the sea at rest, is run only with tide for a few days before the coupling starts. WAM starts with an initial wave field at 00:00 GMT 1st February and the integration runs over $6 \mathrm{~h}$ before coupling. The exchange of information between the models is done every $20 \mathrm{~min}$. Going from an exchange every $20 \mathrm{~min}$ to one every $60 \mathrm{~min}$ just slightly reduces the detail in the tide-induced modulation of wave parameters (Monbaliu et al., 1998). 
Table 2

Description of the experiments in which the information is just passed from the hydrodynamic model to the wave model

\begin{tabular}{ll}
\hline Experiment & Description \\
\hline D2W & $\begin{array}{l}\text { The tide, atmospheric pressure and wind stress computed according to Eq. (3) drive the } \\
\text { hydrodynamic model. The tide- and wind-induced water levels are transferred to } \\
\text { WAM. Time varying currents are not transferred and therefore have no } \\
\text { influence on the wave model }\end{array}$ \\
The hydrodynamic model is driven by tide only. Only the tide-induced currents are \\
transferred to WAM \\
H2W & $\begin{array}{l}\text { The hydrodynamic model is driven by the tide, atmospheric pressure and wind stress computed } \\
\text { according to Eq. (3). Tide- and wind-induced current and water levels are transferred to WAM }\end{array}$ \\
\end{tabular}

The highest level of coupling is when each model has an influence on the other (two-way coupling). The hydrodynamic model is then driven by the surface stress computed by WAM (replacing the surface stress as computed using Eq. (3)), and by the atmospheric pressure and the tide. Tide- and wind-induced currents and water levels from the hydrodynamic model are, in turn, transferred to the wave model. This experiment will be referred to as $\mathrm{WH}$.

Apart from this experiment in the fully coupled mode, others have been made in which information is just passed from one model to the other (one-way coupling). Those dealing with the sensitivity of waves to current are described in Table 2 . The experiments dealing with the sensitivity of surge to waves are summarised in Table 3.

The analysis will mainly be based on time series of differences between model results in one experiment and those obtained in the reference run (Section 3.2.2), for three parameters (significant wave high, peak period and surge elevation) at the five stations listed in Table 1. Computing the value of a global estimator assesses the order of magnitude of the differences between two experiments. The global estimator we have used is defined by

$$
E_{i}(y)=100 \frac{\sqrt{\frac{1}{n} \sum_{k=1}^{n}\left(y_{\mathrm{i}}\left(t_{k}\right)-y_{\mathrm{r}}\left(t_{k}\right)\right)^{2}}}{\sqrt{\frac{1}{n} \sum_{k=1}^{n} y_{\mathrm{r}}^{2}\left(t_{k}\right)}}
$$

where $y$ is one model parameter, $n$ is the number of values in the time series, $y_{\mathrm{i}}\left(t_{k}\right)$ and $y_{\mathrm{r}}\left(t_{k}\right)$ are the values of $y$ at time $t_{k}$ in experiment $\mathrm{i}$ and in the reference run,

Table 3

Description of the experiment in which the information is just passed from the wave model to the hydrodynamic model

\begin{tabular}{ll}
\hline Experiment & Description \\
\hline W2H & $\begin{array}{l}\text { The hydrodynamic model is driven by the tide, atmospheric pressure and wind stress } \\
\text { computed by the wave model }\end{array}$ \\
\hline
\end{tabular}


respectively. Hourly sampled values of model results will be used for the computation of $E$.

\subsection{Sensitivity of waves, tides and surges to coupling}

While Tolman (1990) mainly investigated the influence of tides and surges on waves and Mastenbroek et al. (1993) looked at the influence of a wave-dependent surface stress on surges, both effects are combined in our experiment in fully coupled mode (WH). Therefore, the results from this experiment are analysed first.

Differences in the model variables between WH and the reference run are presented in Fig. 6. The values of $E$ for significant wave height, peak period and surge elevation at the five stations computed from 00:00 GMT 5th February-00:00 GMT 25th February are listed in Table 4.

From Table 4, one can say that the coupling introduces, on the average, a change of less than $5 \%$ in significant wave height, and a change of less than $10 \%$ in peak period and surge elevation. As expected, and to some extent hoped, the coupling does not have a strong influence on the model results. After all, both types of model are used independently by several operational centres and the reliability of the information they deliver does not need to be demonstrated again. However, as discussed below, the differences are interesting in terms of model behaviour and understanding of the physics.

Sensitivity of wave parameters to coupling increases from deep to shallow water. This fact indicates the need to explore the effects of coupling in shallow coastal waters
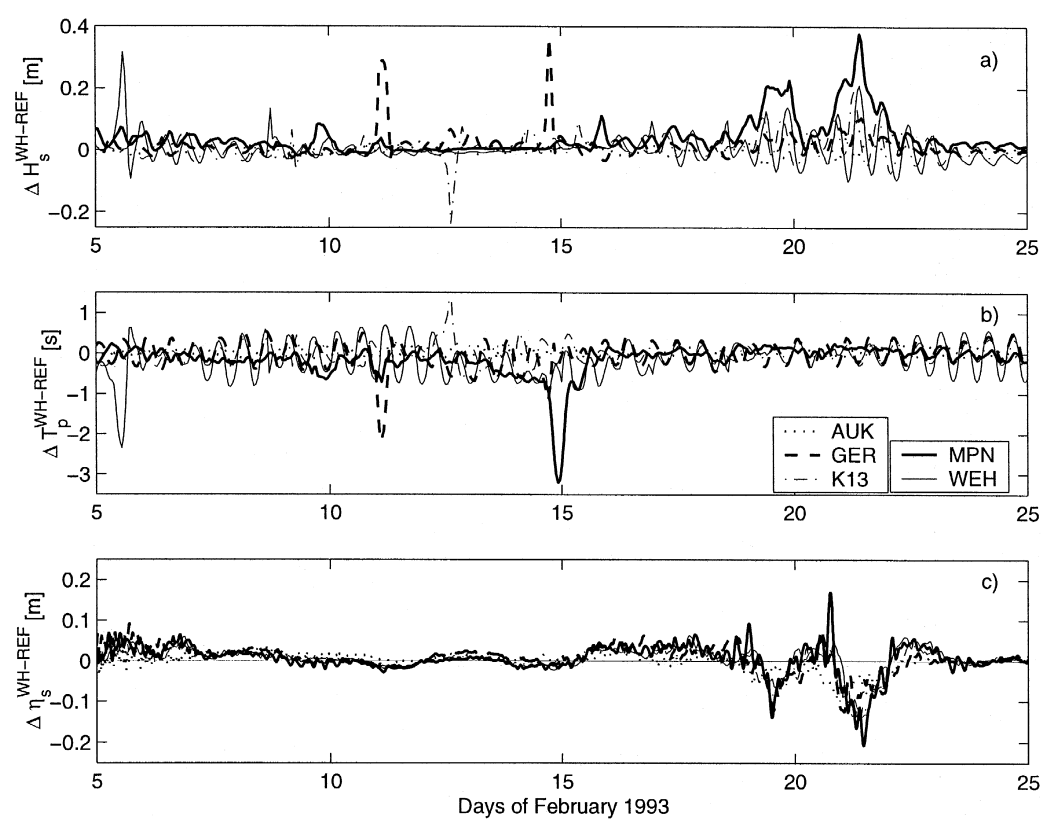

Fig. 6. Time series of differences in $H_{\mathrm{S}}$ (top), $T_{\mathrm{p}}$ (centre) and $\eta_{\mathrm{s}}$ (bottom) between the fully coupled run (WH) and the reference run at the five stations, 5-25th February 1993. 
Table 4

Mean value of $H_{\mathrm{S}}(\mathrm{m}), T_{\mathrm{p}}(\mathrm{s})$ and $\eta_{\mathrm{s}}(\mathrm{m})$ for the reference run and values of the global estimator, $E_{\mathrm{WH}}$, for the differences between the experiment in fully coupled model $(\mathrm{WH})$ and the reference run at five stations computed over the period 5-25th February

\begin{tabular}{lllllll}
\hline Station & $\left\langle H_{\mathrm{S}}\right\rangle$ & $E_{\mathrm{WH}}\left(H_{\mathrm{S}}\right)$ & $\left\langle T_{\mathrm{p}}\right\rangle$ & $E_{\mathrm{WH}}\left(T_{\mathrm{p}}\right)$ & $\left\langle\eta_{\mathrm{s}}\right\rangle$ & $E_{\mathrm{WH}}\left(\eta_{\mathrm{s}}\right)$ \\
\hline Auk & 2.02 & 0.6 & 6.79 & 1.3 & $<0.01$ & 9.6 \\
Ger & 1.30 & 2.8 & 5.90 & 5.2 & 0.07 & 7.8 \\
K13 & 1.36 & 2.0 & 5.72 & 3.9 & 0.02 & 8.0 \\
Mpn & 1.01 & 4.7 & 6.01 & 6.8 & 0.03 & 8.2 \\
Weh & 0.86 & 3.8 & 5.56 & 7.7 & $<0.01$ & 7.2 \\
\hline
\end{tabular}

where modelling with high spatial resolution is needed. Peak period is more sensitive than significant wave height. Tidal modulation of both wave parameters at all stations is clearly visible in the time series of differences almost all of the time (Fig. 6). During the stormy period, wave heights are clearly influenced by coupling. At station Mpn, significant wave height is increased by $38 \mathrm{~cm}$ during the third storm. Tide and surge effects on waves are further discussed in Section 4.2.

Between the 10-15th February, differences between the wave parameters over relatively short time intervals resulting from both experiments are as large as those observed during the stormy period. These are noticeable in the time series of differences in $H_{\mathrm{S}}$ and $T_{\mathrm{p}}$ at stations Ger, K13 and Mpn (see Fig. 6). During these 'events', if significant wave height increase, peak period diminishes (see station Ger) and vice versa (see station K13). At the beginning of such an event, the mean direction of the wave spectrum and that of the wind do not correspond. Currents can accelerate or delay the turning of the wave spectrum towards the direction of the wind. In the former/latter case $H_{\mathrm{S}}$ will grow faster/slower than without currents. In early stages of wave growth, energy is first produced in the high frequency band, then $T_{\mathrm{p}}$ will shift rapidly/slowly to smaller values in the case of accelerated/delayed growth. At station Ger, currents accelerate the turning and growth of the waves. At station K13, they delay it. How far these findings can be attributed to the fact that the WAM wave model does not contain a linear part in the wind input (the so-called Phillips' term) has not been investigated.

The hydrodynamic model results seem to be affected more by coupling than the wave model results. Moreover, even though we observe a small increase in this sensitivity from south to north, it seems to be more or less uniformly distributed over all the North Sea.

In the time series of differences of surge elevations (Fig. 6c), the following observations can be made. After 5 days of integration with the atmospheric forcing, some transients are still present in the response of the hydrodynamic model. The wind does not have a strong influence on the surge elevation before the 15th February. Therefore, after the transients, differences between the two model runs are very small. The influence of the surface stress parameterisation is more obvious during the stormy period. The surge elevations in fully coupled mode during a significant period of time are smaller than in the uncoupled mode especially during the second and third storms. We also observe a modulation of the difference in the surge elevation between the two model runs. Results (not shown here) indicate that this modulation almost disappears 
when a time interpolation of wind speed is made in WAM. However, according to Monbaliu et al. (1999), a linear interpolation in time makes the wave model results less accurate (peak significant wave heights are generally smaller). The time interpolation technique proposed by Killworth (1996) for forcing fields of ocean models could help to solve this problem. With this technique, the mean wind speed felt by the wave model over $6 \mathrm{~h}$ will be as though the wind speed was kept constant, while the surface stress transferred to the surge model will be smoother. The influence of waves on surges is discussed in more detail in Section 4.4.

As the stormy periods are usually of more interest, the analysis of model results in the following sections will be limited to the period from the 00:00 GMT 16th February-00:00 GMT 23rd February.

\subsection{Sensitivity of waves to coupling during storms}

\subsubsection{Overview}

The mean values of $H_{\mathrm{S}}$ for the reference run and the values of the global estimator $E\left(H_{\mathrm{S}}\right)$ for the different experiments in which information is transferred from the hydrodynamic model to the wave model (including the experiment WH already discussed in Section 4.2) are listed in Table 5. The same is done for $T_{\mathrm{p}}$ in Table 6.

Comparing the values of Tables 5 and 6 (last column) with the values of Table 4, it is remarkable that global estimator values in the latter are larger than in the former. Values of $E$ listed in Table $6(\mathrm{WH})$ are smaller than the values in Table 4 especially for the peak period. The nearly continuous tidal modulation of wave parameters and the 'events' observed between the 0 and 15th contribute to these larger values. Part of this also comes from the definition of the global estimator itself (Eq. (5)), where, due to the denominator, periods with small reference signal values are weighted heavier for comparable difference signals.

From the values listed in both tables above, it can be concluded that coupling has a very small influence on wave model results outside the Southern Bight (i.e., above $53^{\circ} \mathrm{N}$ ), at least for the stations considered here. At station Auk, the change in significant wave height and peak period does not exceed $1 \%$. At the stations Ger and K13, the change in significant wave height is less than $2 \%$ and the change in peak period can largely be attributed to a local Doppler effect (see below). The small influence of

Table 5

Mean value of $H_{\mathrm{S}}(\mathrm{m})$ for the reference run and values of the global estimator $E$ for the experiments in which information is transferred from the hydrodynamic model to the wave model. The results reflect the stormy period only

\begin{tabular}{llllll}
\hline Station & $\left\langle H_{\mathrm{S}}\right\rangle$ & $E_{\mathrm{D} 2 \mathrm{~W}}\left(H_{\mathrm{S}}\right)$ & $E_{\mathrm{TC} 2 \mathrm{~W}}\left(H_{\mathrm{S}}\right)$ & $E_{\mathrm{H} 2 \mathrm{~W}}\left(H_{\mathrm{S}}\right)$ & $E_{\mathrm{WH}}\left(H_{\mathrm{S}}\right)$ \\
\hline Auk & 3.71 & $<0.1$ & 0.4 & 0.6 & 0.5 \\
Ger & 2.44 & 1.4 & 0.8 & 2.0 & 1.2 \\
K13 & 2.70 & 1.0 & 1.0 & 1.8 & 1.5 \\
Mpn & 2.09 & 2.9 & 3.3 & 6.1 & 4.8 \\
Weh & 1.18 & 1.3 & 2.9 & 3.3 & 3.0 \\
\hline
\end{tabular}


Table 6

Mean value of $T_{\mathrm{p}}(\mathrm{s})$ for the reference run and values of the global estimator $E$ for the experiments in which information is transferred from the hydrodynamic model to the wave model. The results reflect the stormy period only

\begin{tabular}{llllll}
\hline Station & $\left\langle T_{\mathrm{p}}\right\rangle$ & $E_{\mathrm{D} 2 \mathrm{~W}}\left(T_{\mathrm{p}}\right)$ & $E_{\mathrm{TC} 2 \mathrm{~W}}\left(T_{\mathrm{p}}\right)$ & $E_{\mathrm{H} 2 \mathrm{~W}}\left(T_{\mathrm{p}}\right)$ & $E_{\mathrm{WH}}\left(T_{\mathrm{p}}\right)$ \\
\hline Auk & 8.13 & $<0.1$ & 0.6 & 1.0 & 0.9 \\
Ger & 7.44 & 0.4 & 3.0 & 3.1 & 3.0 \\
K13 & 7.05 & 0.4 & 2.3 & 2.1 & 2.1 \\
Mpn & 6.72 & 0.7 & 1.2 & 1.6 & 1.6 \\
Weh & 6.10 & 0.7 & 3.8 & 3.8 & 3.9 \\
\hline
\end{tabular}

coupling in the German Bight (Ger) may probably be ascribed to the coarse grid used in these experiments. We may expect that, due to the very shallow and complex bottom topography in that area, wave-tide interactions are more important than shown here. For the forecast of waves in coastal areas in the southern North Sea according to the approach described in Section 3.1, a coupled modelling approach does not seem to be required for the coarse grid implementation. This is consistent with the findings of Monbaliu et al. (1998). Model results in the southern North Sea, using a finer grid, were not very sensitive to coupled or uncoupled boundary information. Note that in that application the boundary of the nested grid was still far away from the coast. While this conclusion was drawn from a one-way coupling technique (effect of tides on waves), it is confirmed by the two-way coupling approach used in the present study.

Looking at the significant wave height at the shallow water stations (Ger, K13, Mpn and Weh), we observe that the influence of coupling is almost equally distributed between that due to the time variation of depth (D2W) and that due to tidal currents (TC2W). The values of $E$ in $\mathrm{D} 2 \mathrm{~W}$ and $\mathrm{TC} 2 \mathrm{~W}$ are close and their sum nearly corresponds to the values of $E$ in $\mathrm{H} 2 \mathrm{~W}$. We note also that the influence of coupling is slightly higher in $\mathrm{H} 2 \mathrm{~W}$ than it is in $\mathrm{WH}$. As will be discussed later, we have reasons to believe that it is mainly the reduction of bottom dissipation due to the surge elevation that explains the changes in $H_{\mathrm{S}}$ due to time variation of total depth. Surge elevations due to a wave-dependent surface stress $(\mathrm{W} 2 \mathrm{H}, \mathrm{WH})$ are smaller than those obtained in the reference run. To some extent, one can say that waves have an influence on themselves through their influence on surges.

Looking at the peak period, the influence of coupling seems to be limited to the transformation from relative to absolute frequency at the output except during the 'events' mentioned earlier. In the absence of current (D2W) the peak period is almost as in the reference run. Modulation is due to tidal currents. There is almost no difference between the three experiments with current (TC2W, H2W and WH). The influence of coupling on peak period will not be investigated further. Note that the transformation from relative to absolute frequency space should have no influence on significant wave height. We observed minor differences only, to be attributed to the inherent inaccuracies in the interpolation procedure used.

The influence of coupling is the largest in the Southern Bight, therefore model results in that area are further investigated. 


\subsubsection{Influence of coupling on $H_{S}$ in the Southern Bight}

Time series of differences, with respect to the reference run, in $H_{\mathrm{S}}$ at station K13, Mpn and Weh for the different experiments in which information is passed from the hydrodynamic model to the wave model are presented in Fig. 7.

Coupling seems to have a different influence at the offshore stations (K13 and Weh) than it has at the station near the coast. At the offshore stations a clear tidal modulation of significant wave height is seen in all the experiments in which time varying currents are passed to the wave model. At Mpn, this tidal modulation is less evident.

In the one way-coupling experiments (D2W, TC2W and $\mathrm{H} 2 \mathrm{~W}$ ), the influence of coupling increases with the amount of information that is transferred to the wave model. With time varying depth (D2W), the influence is nearly limited to the two last storms. With time varying currents (TC2W), the tidal modulation is present all the time with an amplitude that increases with increasing $H_{\mathrm{S}}$. Differences in experiment $\mathrm{H} 2 \mathrm{~W}$ are relatively close to the sum of the differences in D2W and TC2W. Wind-induced currents are generally smaller than tidal currents and, therefore, do not significantly change the influence of coupling.

With time-varying depth only (D2W), the propagation speed in the frequency space is still equal to zero (recall that the time derivative of the depth in Eq. (2) is not taken into account). There is no interaction between the waves and the mean flow. Depth refraction is time-dependent through the gradients of the sea surface elevation. In the WAM model, some wave parameters (e.g., wave number, group velocity, phase speed) change
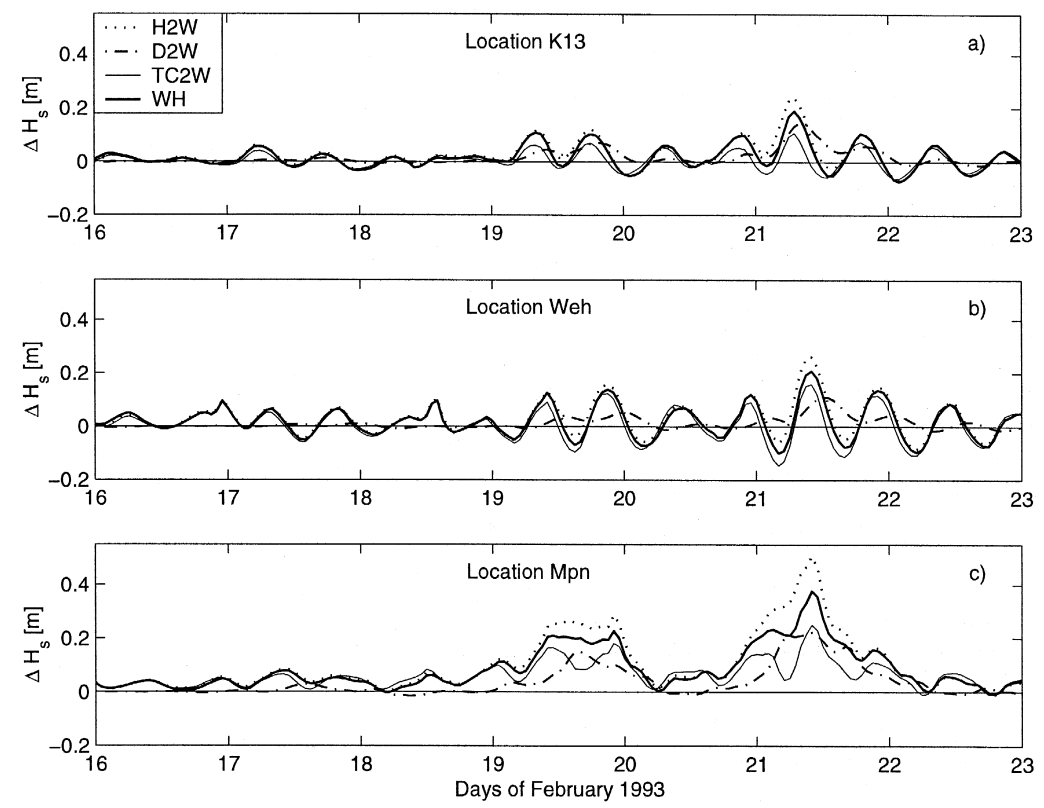

Fig. 7. Time series of differences in $H_{\mathrm{S}}$ at station $\mathrm{K} 13$ (top), Weh (centre) and Mpn (bottom) for all runs relevant to the study on the influence of coupling on waves. 
only if the depth variation modifies the shallow water table index while others (e.g., the bottom friction coefficient) evolve continuously according to the depth.

In Fig. 7, one may observe that the influence of the time-varying depth is nearly limited to the two last storms. In the time series of differences in $H_{\mathrm{S}}$ between D2W and the reference run, oscillations at the tidal frequency are not really observed. Therefore, we argue that the effect of the surge elevation dominates over the effect of the tidal elevation in that experiment. This has been further confirmed by an experiment in which only the tidal elevations were transferred to the wave model. Model results in this experiment were very close to those of the reference run.

During the period of time considered here, neither the tide nor the surge is sufficient to induce a change of the shallow water table index at K13. The wave model at that station has used the same index in all the experiments. At Weh, the tidal elevation already induces a tidal modulation of the index. The same value as in the reference run is used during part of the tidal cycle. A greater value is used during the other part. During the two last storms (19th and 21st) a greater value is used for the whole day. At Mpn, the index may change due to tide only but not in all tidal cycles and only during a small part of the tidal period. As at Weh, due to the surge, a greater value is used during 19th and 21st. As we observe a strong similarity between the differences at the three stations, we suspect that these variations have had a relatively small influence. Therefore, we have to look for another explanation for the influence of the time varying depth.

In the experiments reported here, bottom dissipation in WAM is computed according to Hasselmann et al. (1973)

$$
S_{\mathrm{bf}}=-C_{\mathrm{bf}}(k, d) E(f, \theta)
$$

with $C_{\mathrm{bf}}$ computed according to:

$$
C_{\mathrm{bf}}(k, h)=c \frac{k}{\sinh (2 k d)}
$$

where $c$ is a constant set equal to $7.7 \times 10^{-3} \mathrm{~m} \mathrm{~s}^{-1}$.

In the reference run, a constant depth value is used and the wave number is constant in time for all frequencies. In experiment D2W, $d$ is continuously changing in time and $k$ may evolve as discussed previously. Time series of $C_{\mathrm{bf}}$, evaluated at the peak frequency, have been computed for the reference run and for D2W at all stations. Differences in $C_{\mathrm{bf}}$ together with differences in $H_{\mathrm{S}}$ at the three stations are presented in Fig. 8. At the three stations, there is a significant correlation between differences in $H_{\mathrm{S}}$ and differences in $C_{\mathrm{bf}}$. That is not sufficient to assert that differences in $H_{\mathrm{S}}$ between $\mathrm{D} 2 \mathrm{~W}$ and the reference run are entirely due to the influence of time varying depth on bottom dissipation but that, at least, it has played an important role.

Tidal modulation of $H_{\mathrm{S}}$ due to tidal currents is obvious from the results of experiment TC2W.

With currents, propagation speeds in the spectral space are no more equal to zero. Current refraction is taken into account. The interaction between the waves and the mean flow is turned on. The currents influence the propagation in the geographical space as well. Note that some of these modifications are not applied to all grid points. In the model code, depth and current gradients in all space directions are computed at grid points only if these are surrounded by sea points in both spatial directions. However, at 


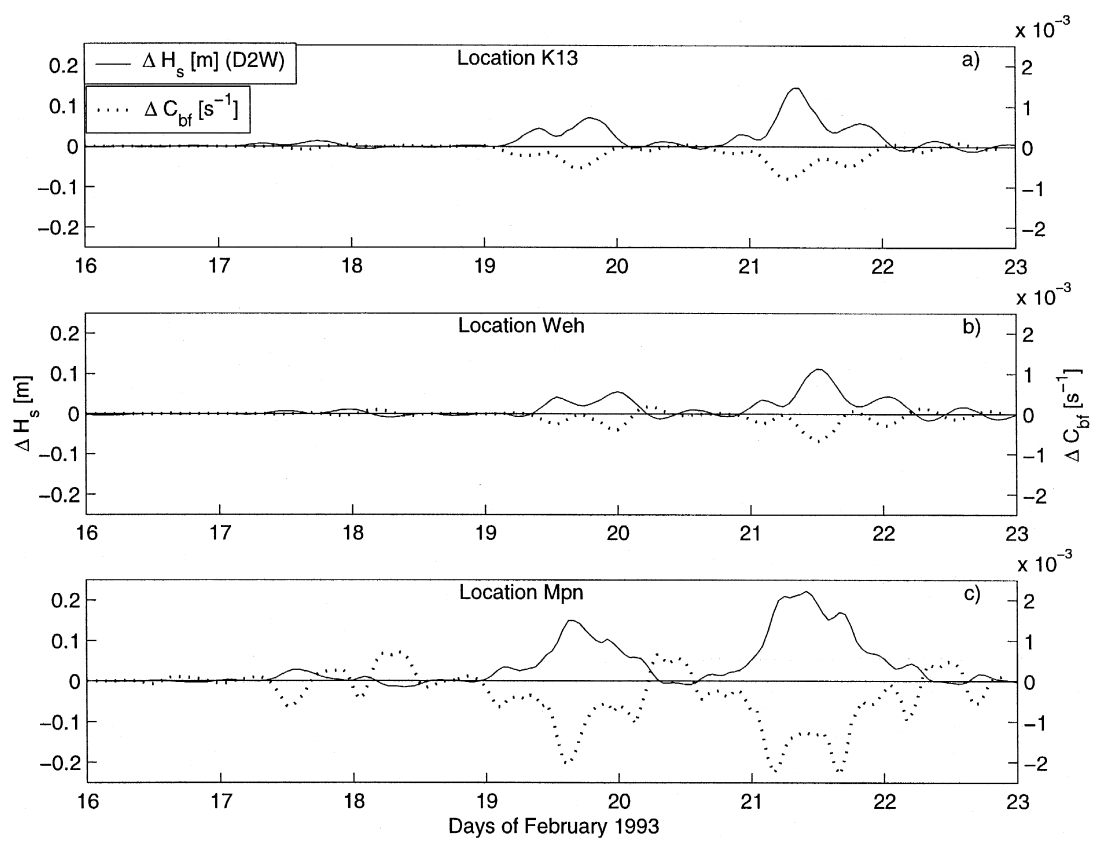

Fig. 8. Time series of $\left(H_{\mathrm{S}}^{\mathrm{D} 2 \mathrm{~W}}-H_{\mathrm{S}}^{\mathrm{REF}}\right)$, solid line, and of $\left(C_{\mathrm{bf}}^{\mathrm{D} 2 \mathrm{~W}}-C_{\mathrm{bf}}^{\mathrm{REF}}\right)$, dashed line, at station $\mathrm{K} 13$ (top), Weh (centre) and Mpn (bottom).

grid points adjacent to the coast, depth and current gradients in the direction perpendicular to the coastline are set equal to zero. One can say that the influence of the hydrodynamic model on the wave model is underestimated all along the coastlines.

Depth and current refraction and the interaction between the waves and the mean flow have a local influence at stations K13 and Weh. Due to the resolution of the grid, the point corresponding to station Mpn is just at a corner (coastline on the east side and on the south side of the mesh). Locally, propagation speeds in the spectral space are equal to zero and there is no interaction between the waves and the mean flow.

At the three stations, differences in $H_{\mathrm{S}}$ due to the tidal current can be seen as the superposition of two main components: one varying with the tidal period and one varying more slowly in time. The amplitude of both components increases with increasing significant wave height. At the two offshore stations (K13 and Weh) the amplitude of the tidal component is the largest. At Mpn, both components have nearly the same amplitude (Fig. 7).

Tolman (1990) suggested that the 'cumulative effects of wave-tide interactions might occur for NW winds (in particular when the waves and the tide propagate in the same direction along the British coast for a long period)'. The wind had been blowing from NW during the stormy period that we have analysed. As the influence of coupling is as large, if not greater, at Mpn than it is offshore, we presume that those cumulative effects have indeed played a role. A complete understanding of the influence of tidal currents on waves in such circumstances cannot be gained by just looking at model results at a 
few points. Nevertheless, such an analysis already provides interesting pieces of information.

Locally, the importance of the wave-tide interactions can be estimated by computing time series of the two following terms (from Eq. (2))

$$
\begin{aligned}
& a_{1}=\frac{1}{\sigma} \frac{\partial \sigma}{\partial d} \vec{u} \cdot \vec{\nabla} d \\
& a_{2}=\frac{c_{\mathrm{g}}}{\sigma} \vec{k} \cdot \frac{\partial \vec{u}}{\partial s} .
\end{aligned}
$$

Both terms are frequency-dependent. For the first one, $a_{1},(1 / \sigma)(\partial \sigma / \partial d)$ decreases rapidly, at all depths, with increasing frequency. For $a_{2}$, the range of variation of $\left(c_{\mathrm{g}} k / \sigma\right)$ is limited to $[0.5,1.0]$. Time series have been computed at the peak frequency calculated during the reference run. For $a_{2}$, the calculation is made in the mean direction of the wave spectrum determined in the reference run. The mean depth is used to estimate the dot product $\vec{u} \cdot \vec{\nabla} d$. The time series are presented in Fig. 9. At both stations, $a_{2}$ is significantly greater than $a_{1}$ (for a mean depth equal to $31.0 \mathrm{~m}$ and a peak frequency equal to $0.1 \mathrm{~s}^{-1},(1 / \sigma)(\partial \sigma / \partial d)$ is only of the order of $\left.0.004 \mathrm{~m}^{-1}\right)$. Clearly, $a_{2}$ dominates in the wave-tide interactions. We have verified that the time derivative of tidal elevation did not strongly modify the values of $a_{1}$, at least at these two stations.

The interaction between the waves and the mean flow is, locally, a source of energy, at all frequencies in the mean direction of the spectrum when $a_{2}$ is negative and a sink
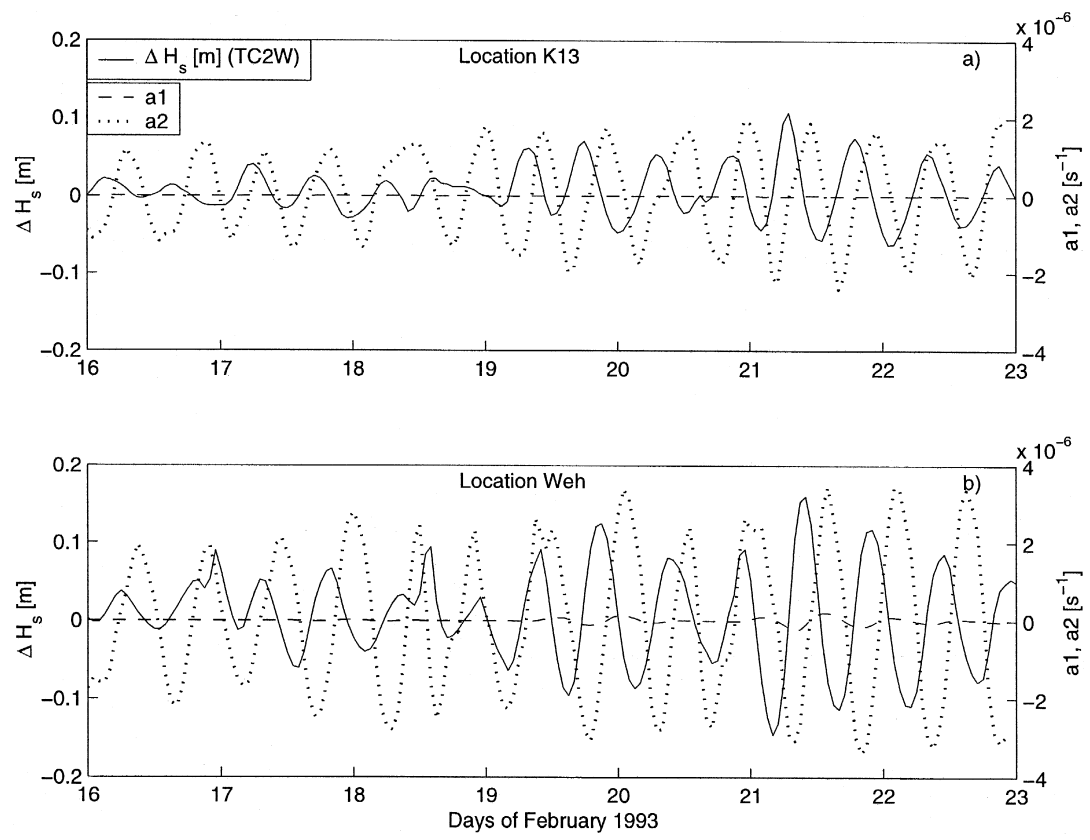

Fig. 9. Time series of $\left(H_{\mathrm{S}}^{\mathrm{TSW}}-H_{\mathrm{S}}^{\mathrm{REF}}\right.$ ), solid line and time series of $a_{1}$ (long dashed line) and $a_{2}$ (short dashed line) at station K13 (top), Weh (centre) and Mpn (bottom). See text for definition of $a_{1}$ and $a_{2}$. 
when it is positive. We observe, in Fig. 9, several periods during which negative/positive values of $a_{2}$ correspond to increasing/decreasing differences in $H_{\mathrm{S}}$ between TC2W and the reference run. Clearly, this process plays a role and as it is directly proportional to the energy density spectrum, it is not surprising to observe increasing modulation with increasing $H_{\mathrm{S}}$.

Now, positive/negative values of $a_{2}$ also correspond to positive/negative propagation velocity in the frequency space. Advection in the frequency space is not a direct source or sink of energy. However, a modulation of the wave parameters can be induced by the adaptation of the spectrum to a new balance.

We have seen in Section 2 that, sometimes, currents can accelerate (or delay) the turning of the wave spectrum in the direction of the wind and hence have a significant influence on the wave parameters. Apart from these 'events', the mean direction of the wave spectrum in the experiment with currents (TC2W) remains relatively close to that in the reference run. There are small differences (of the order of $2^{\circ}$ ) but no significant correlation between this angle deviation and the differences in $H_{\mathrm{S}}$ has been found. Note, however, that the resolution in the directional space is equal to $30^{\circ}$ and therefore relatively coarse.

From the values of the global estimator as well as from the figures, results from experiment $\mathrm{H} 2 \mathrm{~W}$ (tide- and wind-induced current and elevation passed to WAM) has been found close to the sum of those for experiments D2W and TC2W. This is further confirmed in Fig. 10 where differences in $H_{\mathrm{S}}$ between $\mathrm{H} 2 \mathrm{~W}$ and the reference run are
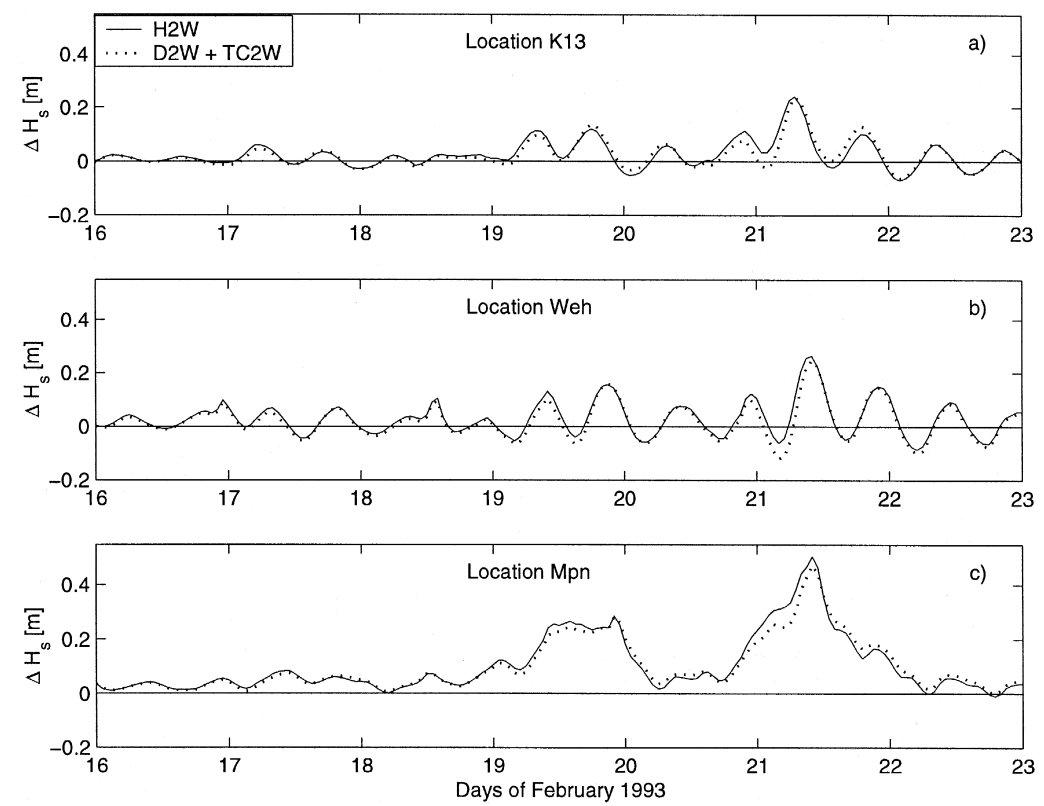

Fig. 10. Time series of $\left(H_{\mathrm{S}}^{\mathrm{H} 2 \mathrm{~W}}-H_{\mathrm{S}}^{\mathrm{REF}}\right)$, solid line, and time series of $\left(H_{\mathrm{S}}^{\mathrm{D} 2 \mathrm{~W}}+H_{\mathrm{S}}^{\mathrm{TC} 2 \mathrm{~W}}+2 H_{\mathrm{S}}^{\mathrm{REF}}\right)$, dashed line, at station K13 (top), Weh (centre) and Mpn (bottom). 
compared to the sum of differences in $H_{\mathrm{S}}$ for D2W and TC2W. The small discrepancies may come from the non-linearity of the model equations and/or from the wind-induced currents.

Significant wave heights in the experiment in fully coupled mode (WH) are slightly smaller than when the information is just passed from the hydrodynamic model to the wave model (H2W). Surge elevations due to wave-dependent surface stresses only (W2H, WH) are generally smaller than those obtained in a conventional run of the hydrodynamic model with surface stress computed according to Heaps (1965) (Eq. (3)) and bottom stress modified to have a component directly related to wind stress (Eq. (4)). This is discussed in the following section. Smaller total depths induce more bottom dissipation and hence smaller significant wave height.

\subsection{Sensitivity of surges to waves}

The influence of wave-dependent surface stress on the surge elevation is investigated with two experiments: W2H (one-way coupling) and WH (two-way coupling). Mean values of the surge elevation in the reference run and the values for the global estimator for the two experiments are listed in Table 7. Time series of differences in $\eta_{\mathrm{s}}$ at K13, Weh and Mpn are presented in Fig. 11.

From Table 7 and Fig. 11, it is clear that the results from both experiments are almost indistinguishable. While differences in significant wave heights have been observed between the experiment in fully coupled mode (WH) and that in one-way coupling $(\mathrm{H} 2 \mathrm{~W})$, this is not the case for surge elevations. In other words, the influence of surge elevation on the wave fields does not significantly modify the wave-dependent surface stress.

With respect to the reference run, the surge elevations computed with the wave-dependent drag coefficient are slightly greater during the first storm and slightly smaller at the peak of the two last storms. For the last one, surge elevations with a wave drag dependent coefficient are up to $20 \mathrm{~cm}(\mathrm{Mpn})$ below the surge elevations in the reference run.

Recall that in the reference run of the hydrodynamic model, the bottom stress is modified so as to have a component directly related to the wind stress (second term of

Table 7

Mean value of $\eta_{\mathrm{s}}(\mathrm{m})$ for the reference run and values of the global estimator $E$, for the experiments in which information is transferred from the wave model to the hydrodynamic model. The results reflect the stormy period only

\begin{tabular}{llcc}
\hline Station & $\left\langle\eta_{\mathrm{s}}\right\rangle$ & $E_{\mathrm{W} 2 \mathrm{H}}\left(\eta_{\mathrm{s}}\right)$ & $E_{\mathrm{WH}}\left(\eta_{\mathrm{s}}\right)$ \\
\hline Auk & 0.21 & 11.4 & 10.0 \\
Ger & 0.49 & 8.1 & 6.9 \\
K13 & 0.36 & 8.8 & 7.7 \\
Mpn & 0.41 & 8.5 & 7.9 \\
Weh & 0.32 & 7.9 & 6.9 \\
\hline
\end{tabular}



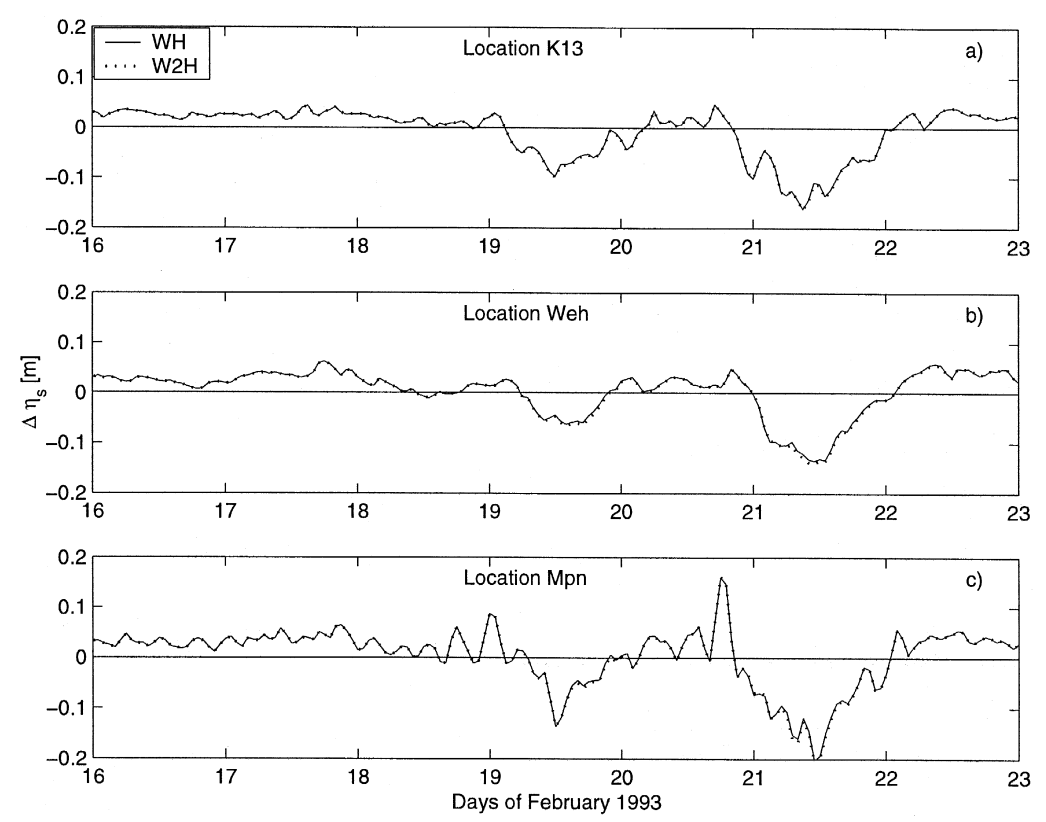

Fig. 11. Time series of $\left(\eta_{\mathrm{s}}^{\mathrm{WH}}-\eta_{\mathrm{s}}^{\mathrm{REF}}\right)$, solid line, and time series of $\left(\eta_{\mathrm{s}}^{\mathrm{W} 2 \mathrm{H}}-\eta_{\mathrm{s}}^{\mathrm{REF}}\right)$, dashed line, at station K13 (top), Weh (centre) and Mpn (bottom).

the right hand side of Eq. (4)). With $m$ equal to 0.1 , this is equivalent to a $10 \%$ increase in the applied surface stress. An experiment equivalent to $\mathrm{W} 2 \mathrm{H}$ with the wave-dependent surface stress multiplied by 1.1 has been performed. With that modification, the surge elevations are greater than in the reference run almost all of the time. Differences, however, never exceed $10 \mathrm{~cm}$. Then, it can be argued that the variation of the drag coefficient with wind speed proposed by Heaps tends to efficiently reflect the increase of the sea surface roughness with increasing wind speed.

From the results of another experiment, one can say that it does it more efficiently than the linear drag coefficient proposed by Smith and Banke (1975). Surge elevations with this latter drag coefficient have always been found to be significantly smaller (up to $45 \mathrm{~cm}$ during the last storm). This is not too surprising. One can easily show that with the Smith and Banke drag coefficient the surface stress is smaller than that computed with the Heaps coefficient for wind speed between 11 and $29 \mathrm{~m} \mathrm{~s}^{-1}$. The largest difference occurs at wind speed equal to $19 \mathrm{~m} \mathrm{~s}^{-1}$. The wind stress is then $30 \%$ smaller than with the Heaps parameterisation. During the three storms, the wind speed never exceeds $25 \mathrm{~m} \mathrm{~s}^{-1}$ in the central and southern parts of the North Sea (see Fig. 3).

The wind stress computed by WAM is a function of the wind speed and the wave age. According to Mastenbroek et al. (1993), the wave-dependent drag coefficient for old wind sea is just slightly larger than the Smith and Banke values. Young wind sea gives rise to drag coefficients up to two times the value of Smith and Banke at the same wind speed. 
Some of the oscillations visible in Fig. 11 have to be attributed to the lack of time interpolation on wind speed in WAM. They are significantly reduced when time interpolation is performed. Without time interpolation, the behaviour of the wave-dependent surface stress is as follows. Each time a new wind field is read, there is a jump in the surface stress (positive for increasing wind speed, negative otherwise). After that the stress still evolves while the wind speed remains constant. A positive jump is followed by a further increase and then, generally, a decrease. A negative jump is followed by a further decrease and then, generally, an increase. This reflects the adaptation of the wave spectrum to the wind field.

The conclusions from these experiments do not differ from those drawn by Mastenbroek et al. (1993). The surge elevations obtained with a wave-dependent drag coefficient can be reproduced with a conventional quadratic law if an appropriate drag coefficient is used. Now, a wave-dependent drag coefficient has the practical advantage in that it directly adapts the surface stress to the characteristics of a particular storm event and to the wave field generated by this storm. It should be therefore preferred. This needs to be confirmed by intensive comparison with in situ data in a wide variety of storm conditions. If it is confirmed, our experiments show that for surge elevations the combined modelling approach is required for the whole area.

In the experiments made by Mastenbroek et al. (1993) in the North Sea, the radiation stress has a relatively small influence on the calculated water levels. In some cases, however, they observe an increase of 10 to 15 when it is included in the calculation. This shows that it cannot be neglected in all cases. Moreover, it is well known that this term is important for applications where depth-induced changes in the waves, as shoaling or breaking, are predominant over propagation and generation, i.e. in coastal areas. It is now included in the momentum equations of the surge model prepared for dissemination and experiments are in progress.

\section{Importance of coupling in other areas of interest for PROMISE}

During the course of PROMISE project, the interactions between waves and currents have been studied in areas other than the North Sea.

Their importance in the Holderness area is discussed at length by Prandle et al. (2000, this volume). In particular, it is shown that the stronger wave influence is confined to the shallower parts of this region.

In the Sylt-Rømø Bight (Schneggenburger et al., 2000, this volume), a significant improvement of the hindcast skill of wave period has been obtained by the inclusion of the currents.

These studies confirmed that the use of a combined modelling approach becomes more important in shallow areas with relatively complex bottom topography. The generic module that has been presented in the previous sections should in principle be able to work in such areas.

The influence of various surface stresses on surge elevations along the Spanish coast has also been investigated. The section of the Spanish coast being studied, and the North 
Sea are two basins of comparable size but with very different characteristics. Hence, it is of particular interest to compare the sensitivity of surge elevations in both areas.

The effect of coupling along the Iberian Atlantic coast was first explored in Alvarez Fanjul et al. (1998). The wave model used is also WAM-cycle4 (WAMDI group, 1988). The hydrodynamic model is the HAMSOM model (Backhaus, 1985; Backhaus and Hainbucher, 1987; Rodriguez et al., 1991; Alvarez Fanjul et al., 1997). A one-way coupling approach is followed. The influence of the spatial gradients of the radiation stress and that of a wave-dependent surface stress (Janssen, 1991) on the surge elevations is investigated. Results show that no practical benefit is obtained. However, the study was limited to a single storm event and, therefore, no possible statistical conclusions could be derived.

To fill this gap, a similar application covering a longer and very stormy period (November 1995-March 1996) is performed. The model output are compared and validated against measurements from the PROMISE Spanish Coast Data set (see Lane et al., 2000, this volume).

Meteorological wind fields provided by the Instituto Nacional de Meteorología and generated by an application of the HIRLAM model ( $30^{\prime}$ resolution) are used to force the WAM model. The model domain covers most of the North Atlantic with a resolution that increases up to $10^{\prime}$ near the Spanish coasts (see Fig. 3 in Carretero Albiach et al., 2000, this volume).

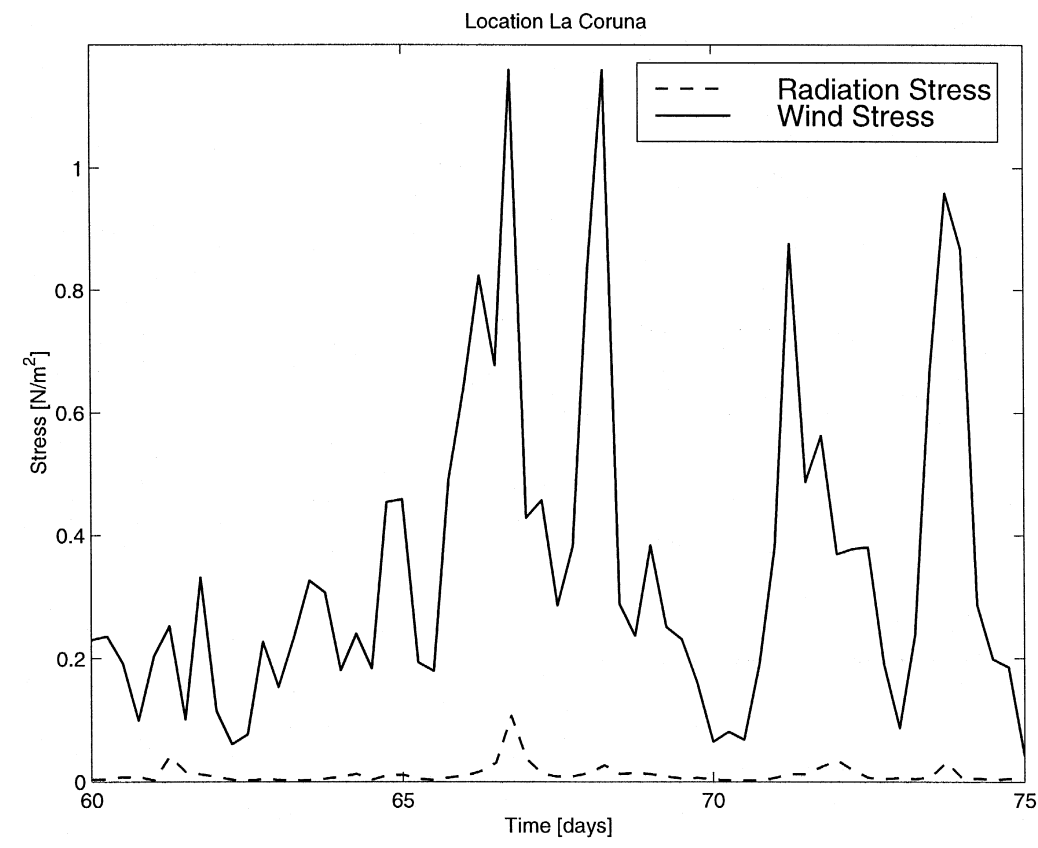

Fig. 12. Comparison between wind stress and spatial gradient of radiation stress at one point near La Coruña. Then period presented corresponds to the first half of January 1996. Four large storm surge events took place during that period. 
The spatial derivatives of the radiation stress derived from the wave spectra are, at this scale and in deep water, negligible with respect to the wind stress. Time series of wind stress and spatial gradient of the radiation stress at one location (La Coruña) are presented in Fig. 12. This result confirms those obtained previously (Alvarez Fanjul et al., 1998), but now over a longer period and for a wide variety of storm events. The result is therefore more meaningful.

Three model runs were performed with the hydrodynamic model. The model domain, the time step and the other model parameters are as in the surge prediction system developed for the Spanish coast and referred to as NIVMAR (see Carretero Albiach et al., 2000, this volume). In the first run, the wind stress is computed according to Smith and Banke (1975). In the second run, a Charnock relationship (Charnock, 1955) is used to relate wind stress to wind speed. In the last run, every $6 \mathrm{~h}$, the wind friction velocity computed by WAM according to Janssen's theory is transferred to the hydrodynamic model. An interpolation in both time and space is performed.

Time series of observed and computed residual at La Coruña are presented in Fig. 13. Results of the statistical analysis are listed in Table 8.

Differences between the three runs are relatively small. However, according to the values of the linear fit, results with a wave-dependent surface stress tend to better agree with the observations.

Contrary to the North Sea, a large part of the area is deep water and the continental shelf is very narrow. Atmospheric pressure forcing tends to dominate over wind stress

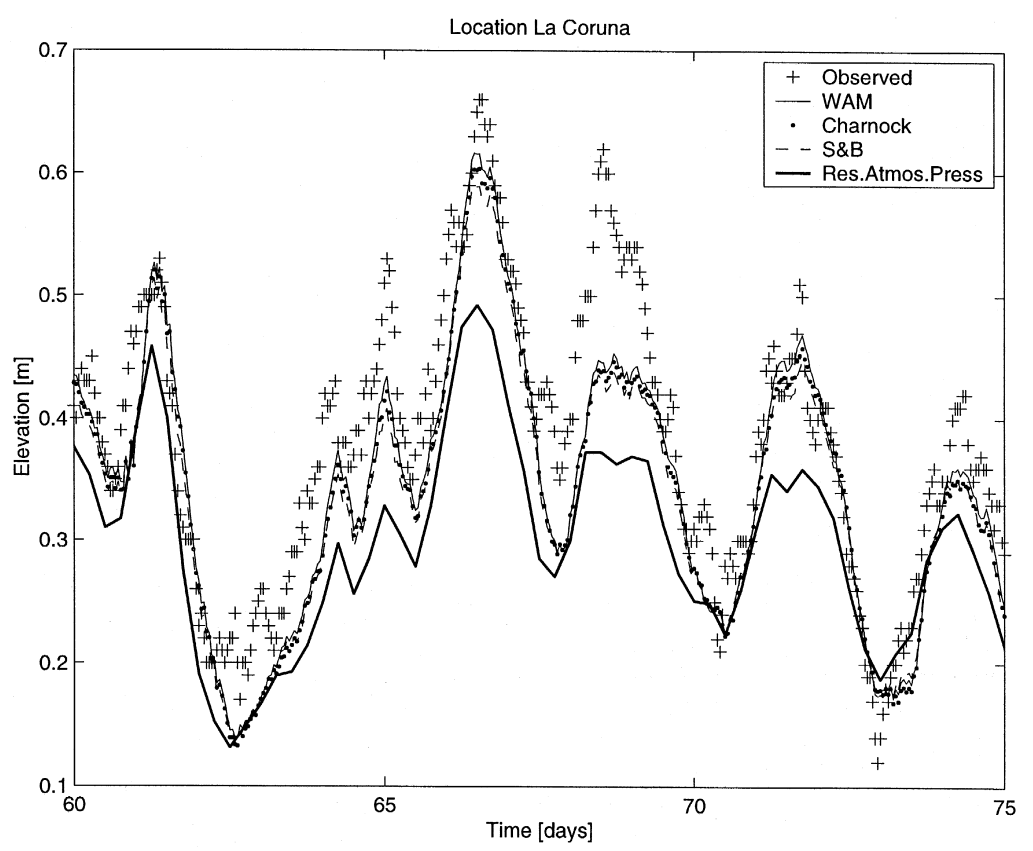

Fig. 13. Observed and computed residuals at La Coruña. Residual due to the inverse barometric affect only is shown. 
Table 8

Statistical comparison between measured and simulated residuals at La Coruña. The number of records that have been used is given in the second column. The mean observed residual is given in the third column. Computed mean residuals have been corrected to this value. RMSE is the root mean square error, RMAX is the maximum error, $m$ and $b$ are the slope and intercept, respectively, of the linear fit and $\mathrm{CI}$ is the correlation index

\begin{tabular}{llllllll}
\hline Model run & No. records & Mean $(\mathrm{cm})$ & RMSE $(\mathrm{cm})$ & RMAX $(\mathrm{m})$ & $m$ & $b(\mathrm{~cm})$ & CI \\
\hline Smith and Banke & 3648 & 17.58 & 5.75 & 20.68 & 0.79 & 3.64 & 0.93 \\
Charnock & 3648 & 17.58 & 5.89 & 20.69 & 0.81 & 3.30 & 0.92 \\
Janssen & 3648 & 17.58 & 5.80 & 20.96 & 0.84 & 2.88 & 0.92 \\
\hline
\end{tabular}

(the residual just due to the inverse barometric effect is shown in Fig. 13). Additional separate runs for pressure and wind indicate that the atmospheric pressure forcing is responsible for roughly $70 \%$ of the residual. Even if there are important changes in the wind-induced part of the surge between the different wind stress parameterisations, the impact on the final residual elevation remains relatively small.

Due to the wider shelf, North Sea surges are wind-dominated. The influence of the atmospheric pressure is small. Moreover, the inverse barometric effect along the open boundaries tends to have a larger influence than that of the pressure gradients.

\section{Summary and conclusions}

A tool that enables combined modelling of tides, surges and waves in shallow water at the North Sea scale has been disseminated. In its preparation for dissemination, existing operational models have been adapted, where necessary, to account for interactions between processes, and implemented in a coupling framework that guarantees efficient and correct exchange of information.

This generic module is then applied to the North Sea and a series of experiments dealing with the sensitivity to coupling of both components of the total motion is performed. From these experiments, the following conclusions can be drawn.

As expected, the coupling has a limited influence on the model results. Both models, taken separately, are run operationally and they deliver information that is reliable.

The larger influence of coupling on wave parameters is confined to the Southern Bight partly due to the horizontal resolution that has been used and partly due to the increase of the mean depth towards the north. In that area, tidal currents have a stronger influence than the tidal elevations. These tidal currents produce a modulation, at the tidal period, of the peak period and of the significant wave height. The former is largely derived from the Doppler shift. The interaction of the wave energy with the mean flow contributed to the latter. During storms, the change in mean depth due to the surge elevation modifies the dissipation of energy due to bottom friction. Higher waves are observed when the increase of the total depth due to the surge elevation is taken into account. 
In the North Sea, the wind plays a key role in the development of surges. Storm surge model results are therefore highly sensitive to wind stress parameterisations. This sensitivity is almost uniformly distributed in space. Within the North Sea, surge elevation observed at one location is rarely the consequence of local effect only. Conventional quadratic laws can produce surge elevations similar to those obtained with a wave-dependent surface stress. However, it is necessary that the drag coefficient can accurately reproduce the increase of the surface roughness with increasing wind speed. In the North Sea experiments reported here, the Heaps' drag coefficient appears to be a better candidate than that proposed by Smith and Banke. Since this roughness is strongly correlated with the wave field, the wave-dependent surface stress should be preferred in storm surge modelling.

Along the Spanish coast, the shelf is much narrower than in the North Sea. Atmospheric pressure tends to dominate over wind stress in the generation of surge elevation in that area. Therefore, even if there are considerable changes in the wind-induced part due to different wind stress parameterisations, the effect on the final residual remains relatively small.

The increasing importance of coupling when going towards shallower areas has been confirmed by the investigations made in the Holderness and the Sylt-Røm $\varnothing$ Bight. Further developments of the generic module presented here precisely involve the setting up, for the hydrodynamic model, of a nesting procedure similar to that available in WAM to allow applications in such coastal areas.

\section{Acknowledgements}

This study was partially undertaken with financial support from the EU MAST III PROGRAMME, contract MAS3-CT9500025. R.A. Flather is thanked for making the bottom topography and some of the results of his Northeast Atlantic model available for the present study. The authors wish to thank PROMISE partners, in particular D. Prandle and D. van den Eynde for stimulating discussions and useful comments on drafts of this paper. The comments made by the two anonymous reviewers were very much appreciated.

\section{References}

Alvarez Fanjul, E., Perez Gomez, B., Rodriguez Sanchez-Arevalo, I., 1997. A description of the tides in the Eastern North Atlantic. Prog. Oceanogr. 40 (1-4), 217-244.

Alvarez Fanjul, E., Gomez, P., Carretero, J.C., Rodriguez Sanchez-Arevalo, I., 1998. Tide and surge dynamics along the Iberian Atlantic Coast. Oceanol. Acta 21 (2), 131-143.

Backhaus, J.O., 1985. A three-dimensional model for simulation of shelf sea dynamics. Dtsch. Hydrogr. Z. 38 (4), 164-187.

Backhaus, J.O., Hainbucher, D., 1987. A finite difference general circulation model for shelf sea and its application to low frequency variability on the North European Shelf. In: Nihoul, J.C.J., Jamart, B.M. (Eds.), Three-dimensional Model of Marine and Estuarine Dynamics. Elsevier Oceanographic Series 45, pp. 221-244. 
Burgers, G.J.H., Flather, R.A., Jansse, P.A.E.M., Mastenbroek, C., Wu, X., Cavaleri, L., 1994. Combining waves and storm surge modelling. In: Komen, G.J. (Ed.), Dynamics and Modelling of Ocean Waves. Cambridge Univ. Press, pp. 371-374.

Carretero Albiach, J.C., Alvarez Fanjul, E., Gómez Lahoz, M., Perez Gomez, B., Rodríguez Sanchez-Arevalo, I. et al., 2000. Ocean forecasting in narrow shelf seas: application to the Spanish coasts. Coastal Eng., This volume.

Cavaleri, L., Flather, R.A., Hasselmann, S., Wu, X., 1994. Shoaling and depth refraction. In: Komen, G.J. (Ed.), Dynamics and Modelling of Ocean Waves. Cambridge Univ. Press, pp. 343-348.

Charnock, H. et al., 1955. Wind stress on a water surface. Q. J. R. Meteorol. Soc. 81, 639-640.

Christoffersen, J.B., Jonsson, I.G., 1985. Bed friction and dissipation in a combined current and wave motion. Ocean Eng. 12, 387-423.

Davies, A.M., Lawrence, J., 1994. Examining the influence of wind and wave turbulence on tidal currents, using a three-dimensional hydrodynamic model including wave-current interaction. J. Phys. Oceanogr. 24, 2441-2460.

Flather, R.A., 1981. Results from a model of the north east Atlantic relating to the Norwegian Coastal Current. In: Sætre, R., Mork, M. (Eds.), The Norwegian Coastal Current, Proceedings of the Norwegian Coastal Current Symposium, Geilo, 9-12 September 1980 vol. II, pp. 427-458.

Flather, R.A., 2000. Existing operational oceanography. Coastal Eng., This volume.

Groen, P., Groves, G.W., 1962. Surges. In: Hill, M.N. (Ed.), The Sea vol. 1 Wiley, New York, NY, pp. 611-646.

Gross, T.F., Isley, A.E., Sherwood, C.R., 1992. Estimation of stress and bed roughness during storms on the Northern California Shelf. Cont. Shelf Res. 12 (2/3), 389-413.

Günther, H., Hasselmann, S., Janssen, P.A.E.M., 1992. The WAM model Cycle 4. Report No. 4, Hamburg.

Hasselmann, K., Barnett, T.P., Bouws, E., Carlson, H., Cartwright, D.E., Enke, K., Ewing, J.I., Gienapp, H., Hasselmann, D.E., Kruseman, P., Meerbrug, A., Müller, P., Olbers, D.J., Richter, K., Sell, W., Walden, H., 1973. Measurements of wind-wave growth and swell decay during the Joint North Sea Wave Project (JONSWAP). Dtsch. Hydrogr. Z. A8 (12), 95 pp.

Hasselmann, S., Hasselmann, K., Allender, J.H., Barnett, T.P., 1985. Computations and parameterizations of the nonlinear energy transfer in a gravity-wave spectrum: Part. II. Parameterizations of the nonlinear energy transfer for application in wave models. J. Phys. Oceanogr. 15, 1378-1391.

Heaps, N.S., 1965. Storm surges on a continental shelf. Philos. Trans. R. Soc. London, Ser. A 257, 351-383.

Heaps, N.S., 1967. Storm surges. In: Barnes, H. (Ed.), Oceanography and Marine Biology Annual Review. Allen and Urwin, London, pp. 11-47.

Heaps, N.S., 1983. Storm surges 1967-1982. Geophys. J. R. Astron. Soc. 74, 331-376.

Janssen, P.A.E.M., 1989. Wave-induced stress and the drag of the air flow over sea waves. J. Phys. Oceanogr. 19, 745-754.

Janssen, P.A.E.M., 1991. Quasi-linear theory of wind-wave generation applied to wave forecasting. J. Phys. Oceanogr. 21, 1631-1642.

Killworth, P.D., 1996. Time interpolation of forcing fields in ocean models. J. Phys. Oceanogr. 26, 136-143.

Komen, G.J., Cavaleri, L., Donelan, M., Hasselmann, K., Hasselmann, S., Janssen, P.A.E.M., 1994. Dynamics and Modelling of Ocean Waves. Cambridge Univ. Press, Cambridge, $532 \mathrm{pp}$.

Lane, A., Riethmüller, R., Herbers, D., Rybaczok, P., Günther, H., Baumert, H., 2000. Observational data sets for model development. Coastal Eng., This volume.

Le Blond, P.H., Mysak, L.A., 1978. Waves in the Ocean. Elsevier, Amsterdam.

Maat, N., Kraan, C., Oost, W.A., 1991. The roughness of wind waves. Boundary Layer Meteorol. 54, 89-103.

Madsen, O.S., 1994. Spectral wave-current bottom boundary layer flows. Proceedings of the 24th International Conference on Coastal Engineering. Coastal Engineering Research Council/ASCE, Kobe, pp. 384-398.

Makin, V.K., Chalikov, D.V., 1986. Calculating momentum and energy fluxes going into developing waves. Izv., Atmos. Ocean Phys. 22, 1015-1019.

Mastenbroek, C., Burgers, G., Janssen, P.A.E.M., 1993. The dynamical coupling of a wave model and a storm surge model through the atmospheric boundary layer. J. Phys. Oceanogr. 23, 1856-1866.

Monbaliu, J., 1994. On the use of the Donelan wave spectral parameter as a measure for the roughness of wind waves. Boundary Layer Meteorol. 67, 277-291. 
Monbaliu, J., Zhang, M.Y., de Bakker, K., Hargreaves, J., Luo, W., Flather, R., Carretero, J.C., Gomez Lahoz, M., Lozano, I., Stawartz, M., Günther, H., Rosenthal, W., Ozer, J., 1997. WAM model intercomparisons - North Sea. Proudman Oceanographic Laboratory Report No. 47.

Monbaliu, J., Yu, C.S., Osuna, P., 1998. Sensitivity of wind-wave simulation to coupling with a tide/surge model - with application to the southern North Sea. Proceedings of the 26th International Conference on Coastal Engineering, Copenhagen. pp. 945-957.

Monbaliu, J., Hargreaves, J., Carretero, J.-C., Gerritsen, H., Flather, R., 1999. Wave modelling in the PROMISE project. Coastal Eng., 379-407, special issue on SCAWVEX.

Monbaliu, J., Padilla-Hernández, R., Hargreaves, J.C., Carretero Albiach, J.C., Luo, W., Sclavo, M., Günther, H., 2000. The spectral wave model WAM adapted for applications with high spatial resolution. Coastal Eng., This volume.

Ovidio, F., Bidlot, J.R., van den Eynde, D., 1995. Validation and improvement of the quality of the operational wave model MU-WAVE by the use of ERS-1 satellite data, MUMM/T3/AR05. Final Report European Space Agency Pilot Project PP2-B9.

Phillips, O.M., 1977. The Dynamics of the Upper Ocean. Cambridge Univ. Press, 336 pp.

Prandle, D., 2000. Operational oceanography in coastal waters. Coastal Eng., This volume.

Prandle, D., Hargreaves, J.C., McManus, J.P., Campbell, A.R., Duwe, K., Lane, A., Mahnke, P., Shimwell, S., Wolf, J., 2000. Tide, wave and suspended sediment modelling on an open coast - Holderness. Coastal Eng., This volume.

Rodriguez, I., Alvarez, E., Krohn, J., Backhaus, J., 1991. A mid-scale tidal analysis of waters around the north-western corner of the Iberian Peninsula. Proceedings book from 'Computer modelling in ocean engineering 91', Balkema.

Ronday, F.C., 1976. Modèles hydrodynamiques. Projet Mer, Rapport Final, Services du Premier Ministre, Programmation de la Politique Scientifique, Brussels, Belgium, 270 pp.

Schneggenburger, C., Günther, H., Rosenthal, W., 2000. Spectral wave modelling with non-linear dissipation: validation and application in a coastal tidal environment. Coastal Eng., This volume.

Smith, S.D., Banke, E.G., 1975. Variation of the sea surface drag coefficient with wind speed. Q. J. R. Meteorol. Soc. 101, 665-673.

SWAMP group, 1985. Sea wave modelling project (SWAMP). An intercomparison study of wind wave predictions models: Part 1. Principal results and conclusions. Ocean Wave Modelling. Plenum, New York, $256 \mathrm{pp}$.

Tolman, H.L., 1990. Wind wave propagation in tidal seas. Commun. Hydraul. Geotech. Eng., January, Delft University of Technology, $135 \mathrm{pp}$.

van den Eynde, D., Scory, S., Malisse, J.-P., 1995. Operational modelling of tides and waves in the North Sea on the Convex C230 at MUMM. European Convex User's Conference 1995, 24-27 October 1995, Brussels, Belgium.

WAMDIgroup, 1988. The WAM model - a third generation ocean wave prediction model. J. Phys. Oceanogr. 18, 1775-1810.

Wolf, J., 1999. The estimation of shear stresses from near-bed turbulent velocities for combined wave-current flows. Coastal Eng. 37, 529-543.

Wolf, J., Prandle, D., 1999. Some observations of wave-current interaction. Coastal Eng. 37, 471-485.

Wolf, J., Hubbert, K.P., Flather, R.A., 1988. A feasibility study for the development of a joint surge and wave model. Proudman Oceanographic Laboratory Report No. 1, 109 pp.

Wu, X., Flather, R.A., 1992. Hindcasting waves using a coupled wave-tide-surge model. Third International Workshop on Wave hindcasting and forecasting, Montreal, Quebec, May 19-22. pp. 159-170, Environment Canada, Prepints. 